\title{
Field tests of a general ectotherm niche model show how water can limit lizard activity and distribution
}

\author{
Michael R. Kearney, ${ }^{1,7}$ Suzanne L. Munns, ${ }^{2}$ Danae Moore,,${ }^{3,4}$ Matthew Malishev, ${ }^{1,5}$ and C. Michael Bull ${ }^{6}$ \\ ${ }^{1}$ School of BioSciences, The University of Melbourne, Parkville, Victoria 3010 Australia \\ ${ }^{2}$ College of Public Health, Medical and Veterinary Sciences, James Cook University, Townsville, Queensland 4810 Australia \\ ${ }^{3}$ Department of Biological Sciences, Macquarie University, North Ryde, New South Wales 2109 Australia \\ ${ }^{4}$ Australian Wildlife Conservancy, Newhaven Wildlife Sanctuary, P.M. B. 146, Alice Springs, Northern Territory 0872 Australia \\ ${ }^{5}$ Centre of Excellence for Biosecurity Risk Analysis, School of BioSciences, The University of Melbourne, Parkville, Victoria 3010 Australia \\ ${ }^{6}$ School of Biological Sciences, Flinders University, Adelaide, South Australia 5001 Australia
}

\begin{abstract}
Mechanistic forecasts of how species will respond to climate change are highly desired but difficult to achieve. Because processes at different scales are explicit in such models, careful assessments of their predictive abilities can provide valuable insights that will be relevant to functionally similar species. However, there are surprisingly few comprehensive field tests of mechanistic niche models in the literature. We applied a general, thermodynamically grounded modeling framework to determine the fundamental niche of an extremely well-studied herbivorous ectotherm, the sleepy lizard Tiliqua rugosa. We then compared the model predictions with detailed long-term field observations that included sub-hourly data on microclimate, activity levels, home ranges, and body temperatures as well as annual to decadal patterns of body condition and growth. Body temperature predictions inferred from gridded climatic data were within $10 \%$ of empirically observed values and explained $>70 \%$ of observed daytime activity patterns across all lizards. However, some periods of activity restriction were explained by predicted desiccation level rather than by temperature, and metabolically driven activity requirements were much lower than potential activity time. Decadal trajectories of field growth and body condition could also be explained to within $10 \%$ of observed values, with the variance in trajectories being attributable to whether individuals had access to permanent water. Continent-wide applications of the model partly captured the inland distribution limit, but only after accounting for water limitations. Predicted changes in habitat suitability under six climate change scenarios were generally positive within the species' current range, but varied strongly with predicted rainfall. Temperature is regarded as the major factor that will restrict the distribution and abundance of lizards and other terrestrial ectotherms under climate change. Yet our findings show how water can be more important than temperature in constraining the activity, habitat requirements, and distribution limits of terrestrial ectotherms. Our results demonstrate the feasibility of first-principles computation of the climatic limits on terrestrial animals from gridded environmental data, providing a coherent picture for how species will respond to climate change at different scales of space and time.
\end{abstract}

Key words: activity restriction; biophysical model; climate; ectotherm; energy budget; field-validation; mechanistic niche model; water budget.

\section{INTRODUCTION}

A major goal in ecology today is to forecast the effects of climate change on biodiversity (Mouquet et al. 2015, Urban et al. 2016). A predictive understanding of the connection between weather, climate, and the distribution and abundance of species has always been a fundamental ecological topic (Warming 1909, Uvarov 1931, Andrewartha and Birch 1954). But, with the entire climate system shifting through anthropogenic warming, improving this predictive capacity is now a major applied goal in conservation and biodiversity management (Hughes 2000, Parmesan 2006, Urban 2015). A general theme in ecological forecasting is the distinction between descriptive, empirical models and mechanistic, explanatory ones (Dormann et al. 2012, Mouquet et al. 2015, Petchey et al. 2015). Urban et al. (2016) recently reviewed the state of the art of forecasting climate change

Manuscript received 13 September 2017; revised 10 March 2018; accepted 4 June 2018. Corresponding Editor: David Nogues Bravo.

${ }^{7}$ E-mail: mrke@unimelb.edu.au impacts on biodiversity and emphasized the importance of mechanistic models for predictions under novel environments, echoing previous work (Davis et al. 1998, Veloz et al. 2012). They acknowledged the often restrictive data requirements for mechanistic models. But they also pointed out that detailed examinations of a few carefully studied cases can be of great value in dissecting the nature of the underlying processes by which climate constraints species, whether the models succeed or fail.

Computational tools now exist for landscape-scale modeling of microclimate and physiological responses at nearhourly scales, and translating them via life history responses to vital rates at lifetime scales (Porter et al. 2002, Buckley 2008, Kearney 2012, Briscoe et al. 2016, Levy et al. 2016). This means they can mechanistically connect demographic processes to environmental controls on vital rates: a key goal in population biology (Ehrlén and Morris 2015). However, the value of such modeling attempts must be assessed through detailed ground-truthing at the relevant temporal scales of the predictions made by these models. Unlike correlative modeling exercises, mechanistic niche models make 
very explicit predictions about the state of individuals at different scales, ranging from body temperature and activity windows to trajectories of body condition, growth, and reproduction. These kinds of data are often more tractable to collect in the field than are population-related phenomena (e.g., population growth rate, age, and size structure), but mechanistic niche modeling exercises are rarely validated against them in detail, the focus typically being on the plausibility and correspondence of the higher-level outputs compared with observations (Kearney and Porter 2004, Crozier and Dwyer 2006, Buckley 2008, 2010, Kearney et al. 2008, 2009a, Kearney 2012, Levy et al. 2016, 2017, Riddell et al. 2017). For example, in our own work, detailed validation of sub-processes has been limited to coarse field metabolic rates (Kearney and Porter 2004), predicted individual movement compared to observed rate of range expansion (Kearney et al. 2008), and limited tests against field growth rates (Kearney 2012). Without more detailed field verification, apparently successful mechanistic predictions of distribution limits could be seen as merely sophisticated environmental indices that happen to correlate with distribution and abundance. If mechanistic models are making the right predictions for the wrong reasons, they may lead to incorrect management decisions and inaccurate forecasts. Moreover, investigations into the failures of a mechanistic niche model to predict observations may lead to new insights into the limiting processes.

Air temperature and rainfall are strong predictors of terrestrial species' ranges in correlative species distribution models. A key question in mechanistic niche modeling is, therefore, how temperature and water causally connect to distribution and abundance (Briscoe et al. 2016). The effects of temperature and thermoregulation on the activity budgets and distribution limits of terrestrial ectotherms are well understood (Huey 1982, Dunham et al. 1989, Adolph and Porter 1993, Hertz et al. 1993, Angilletta 2009, Huey et al. 2012, Kearney 2012, 2013). There has been a strong focus on the direct effects of climate warming in limiting the distribution of ectotherms (Deutsch et al. 2008, Tewksbury et al. 2008, Huey et al. 2009, 2010, Dillon et al. 2010). This is because high temperature often restricts ectotherm activity while simultaneously increasing metabolic rate and decreasing performance (Dunham 1993, Dillon et al. 2010, Huey et al. 2012). However, the importance of such direct temperature effects depends on the availability of buffering microhabitats as well as the extent to which activity time is limiting (Kearney et al. 2009b, Kearney 2013, Levy et al. 2017). These potentially negative impacts of warming may be countered by the positive effects of faster assimilation, growth, and reproduction in many circumstances (Kearney 2013, Levy et al. 2017).

In contrast to temperature, we know conspicuously little about the role of water budgets in limiting terrestrial ectotherms (Bradshaw 1977, Tracy et al. 2014). Evaporative water loss is very low in "dry-skinned" ectotherms, such as reptiles and insects, compared to "wet-skinned" animals such as amphibians and molluscs. Reptiles are preadapted to aridity (Bradshaw 1986) and desert-adapted species often show reduced cutaneous water loss (Roberts and Lillywhite 1980) as well as an ability to tolerate high osmolality (Bradshaw 1970). Yet even desert-adapted reptiles typically lose more than $70 \%$ of their total evaporative water through their skin (Bentley and Schmidt-Nielsen 1966, Eynan and Dmi'el 1993) as well as large absolute amounts through their feces (Nagy 1972, Porter et al. 1973), and can therefore be vulnerable to desiccation in dry habitats. This may result in animals ceasing activity to reduce water loss during apparently thermally suitable times (Nagy 1972) or commencing activity to access water during thermally unsuitable times (Lorenzon et al. 1999, Chown et al. 2004, Kerr and Bull 2004, Seely et al. 2005, Davis and DeNardo 2010). The few studies on this topic illustrate how important water balance can be to "dry-skinned" ectotherms. Activity restriction because of heat stress has become a focus of climate change studies of reptiles (Sinervo et al. 2010, Medina et al. 2012, Ceia-Hasse et al. 2014), but activity restriction due to water stress may be a more potent limitation (Pirtle et al., in press).

There are also strong indirect effects of climate change on the availability of water for organisms. All else being equal, climate warming will increase vapor pressure deficits and thus increase organismal evaporation rates. For the same reason, warming will reduce available soil moisture, with indirect effects of reduced prey availability and food water content as well as potential nesting failures for egg layers (Packard and Packard 1988, Reedy et al. 2013). When coupled with decreased rainfall, as is predicted in many parts of the planet under climate change, these soil moisture-driven responses will be exacerbated (Dai 2013). An integrated understanding of the constraints that environments impose on heat and water budgets is therefore necessary to understand the present and future distribution limits for many organisms (Chown et al. 2011, Kearney et al. 2013).

To explore these issues of predictive capacity of mechanistic niche models and the relative roles of temperature and water in climatic responses, we apply a recently developed modeling system, NicheMapR (Kearney et al. 2013, Kearney and Porter 2017) to compute the full energy and mass budget of the Australian sleepy lizard Tiliqua rugosa, i.e., the "thermodynamic niche" (Kearney et al. 2013). The modeling system integrates biophysical principles of heat and water exchange with a formal metabolic theory (Dynamic Energy Budget [DEB] theory, Kooijman 2010) for computing the uptake and allocation of energy and matter across the whole life cycle (Kearney 2012, 2013, Kearney et al. 2013). The modeling framework is highly generalizable in that the same model structure and parameters are used for any kind of ectothermic species, with only the particular values of the parameters varying among taxa (the standard DEB model, as implemented in this analysis, applies to the vast majority of species but some groups, e.g., the insects, may require a variant on the standard DEB model, e.g., Llandres et al. 2015 and Maino et al. 2016). The approaches to model development, testing, and implementation described here can therefore be used as a template for modeling other ectothermic species.

Previous tests of the modeling framework have shown that the microclimate model we used can accurately predict hourly conditions from daily gridded environmental data (Kearney et al. 2014). This microclimate model has recently been extended to compute soil moisture (Kearney and Porter 2017), from which plant growth limitation and hence food and water availability can be inferred. The integrated 
biophysical/DEB model has been used previously to consider thermal limits on reptile distribution (Kearney 2012) as well as other thermally related responses (Kearney 2013, Schwarzkopf et al. 2016). However, the system's capacity to predict hydric limitations on activity, growth, and distribution has not been tested, nor has its ability to capture finescale body temperature and activity patterns.

The sleepy lizard, a species from southern temperate and semiarid Australia, is an ideal species with which to test the capacity of the NicheMapR mechanistic niche modeling system. Its natural history and population ecology are well understood after more than four decades of work by Bull and colleagues (Bull 1987, Bull et al. 1991, 1998, Kerr et al. 2003, Kerr and Bull 2006b, Jones et al. 2016). This includes a mark-recapture study that provides decadal-scale length and mass data for individual lizards (Jones et al. 2016). Detailed life history data are available for this species for fitting the DEB model (Bull et al. 1993) as well as extensive ecophysiological data (Bentley 1959a, b, Warburg 1965, Wilson 1974). Activity patterns and field body temperature in this species are also extremely well described from a longterm study of their social behavior at a semiarid site (Bull et al. 2012, Godfrey et al. 2014). In this study, we compare our model predictions against high frequency ( $2 \mathrm{~min}$ ) empirical observations of body temperature and times of activity of 61 lizards during the spring and early summer of 2009 and 2010. We also compare our predictions against body mass observations over this time period and during the 2002-2003 drought and against body length and mass trajectories of 29 lizards over a $30-y r$ period. Specifically, we assess the extent to which such a modeling system, driven by interpolated weather data available at the continental scale, can coherently capture observed patterns of body temperature, activity, growth, and body condition in this lizard at this site, and we deduce the relative roles of temperature and water in explaining these patterns. We also consider the distinction between available activity time, as inferred by the biophysical model alone, and required activity time, as determined by the integrated biophysical and metabolic models. We then apply the model at the continental scale to infer the relative roles of hydric and thermal constraints in limiting the distribution of ectotherms under contemporary and future climate scenarios.

\section{Methods \\ Lizard activity observations}

The empirical field data were collected from August to December in 2009 and 2010, in a $1.0 \times 1.5 \mathrm{~km}$ area of chenopod shrubland $\left(33.888^{\circ} \mathrm{S}, 139.311^{\circ} \mathrm{E}\right)$, near Bundey Bore Station in the mid-north region of South Australia (Bull et al. 1991). The study period was during the austral spring and early summer of each year, and included almost the entire activity period for these lizards (Kerr and Bull 2006a, Kerr et al. 2008).

Adult sleepy lizards resident in the area were captured by hand in late August and early September of each year (2009, $n=61 ; 2010, n=60$ ) and data loggers (Kerr et al. 2004) were attached to the dorsal surface of the tail with surgical tape. These recorded the number of steps taken, the temperature on the dorsal tail surface every $2 \mathrm{~min}$, and the GPS location every $10 \mathrm{~min}$, of every day during the study period. Lizards were recaptured every two weeks to download these data and replace logger batteries. We considered that a lizard had emerged from its refuge and was actively moving during an hour if it took more than 50 steps. While this may have underestimated the number of hours when active per day, it avoided including cases where lizards only made small movements within refuge retreats.

\section{Lizard growth and condition observations}

To test model predictions of environmental sensitivity of growth and body condition, we used field observations of length and mass from the long-term mark-recapture data set on T. rugosa at the study area (Bull 1987, 1995, Jones et al. 2016). A total of 29 individuals were chosen based on having 50 or more observations, which spanned periods per individual of between 11 and 30 yr between 1983 and 2013.

\section{Life history observations in captivity}

Data for DEB model fitting (see Dynamic energy budget model) were obtained from a breeding colony at James Cook University, Townsville, Queensland established from adult lizards captured in October 2006 near the field site. The animals were housed communally with a seasonally variable thermal gradient $\left(8^{\circ}-12^{\circ} \mathrm{C}\right.$ winter and $20^{\circ}-40^{\circ} \mathrm{C}$ summer), with full spectrum lighting, free access to water, and a diet of mixed fruit and vegetables, tinned cat food, boiled eggs, insects, and vitamin and mineral supplements (RepCal and Herptivite, Rep-Cal ${ }^{\circledR}$ Research Labs, Los Gatos, CA, USA). Lizards were weighed weekly during the summer active season and monthly during the inactive winter season. Environmental temperatures within the housing facility were measured hourly throughout the year at the lower and higher ends of the thermal gradient using temperature data loggers and associated software (TinyTag TGU-4500 and TGU4020; TinyTag Explorer Software, Version 4.8, Hastings data loggers, Port Macquarie, New South Wales, Australia).

\section{Biophysical modeling}

We used the R package NicheMapR v1.3 (Kearney and Porter 2017), which has two components: a microclimate model and an ectotherm model ( $\mathrm{R}$ package available online). ${ }^{8}$ The code specific to this analysis can also be found online. ${ }^{9}$ The microclimate model, when applied in Australia using interpolated daily weather data (air temperature, rainfall, wind speed, vapor pressure, and solar radiation) and a continent-wide soil database as input, can predict hourly soil temperatures within $10 \%$ of observed values across a wide range of environments (Kearney et al. 2014, Kearney and Maino 2018). We implemented the model as reported in Kearney et al. (2014) with two additions. First, we integrated a daily gridded mean wind speed product (McVicar et al. 2008), assuming maximum wind speed was double, and minimum wind speed was half, the mean value (Kearney

\footnotetext{
${ }^{8}$ https://github.com/mrke/NicheMapR

${ }^{9}$ https://zenodo.org/badge/latestdoi/40096662
} 
et al. [2014] used long-term monthly mean values). Second, we incorporated a soil moisture model (Campbell 1985, Kearney and Maino 2018), primarily to model the dynamics of the sleepy lizard food plants and burrow humidity (see Dynamic energy budget model and Modeling food and its water content). We ran the microclimate model for the geographical coordinates of the Bundey Bore study site for each day of the years 1991-2010. The model was run for two extremes of shade, allowing spatially implicit thermoregulatory behavior (see Malishev et al. [2017] for an example of a spatially explicit implementation).

The outputs of the microclimate model were then used as inputs for the ectotherm model, which computes the steadystate body temperature, evaporative water loss, activity time, and habitat selection of an organism under specific microclimatic conditions and given behavioral constraints on an hourly time step (Porter et al. 1973, Kearney et al. 2013). The parameters for the ectotherm model are summarized in Table 1.

We simulated the lizard to emerge and forage between body temperatures of $26-39^{\circ} \mathrm{C}$, based on field cloacal temperature measurements of active sleepy lizards (Pamula 1997), and on temperatures selected in laboratory thermal gradients (Wilson 1974). Lizards were assumed to forage in open microhabitats from $0 \%$ to $50 \%$ shade, representing the approximate range of open to shaded ground in their habitat. Sleepy lizards typically respond to high temperature during the day by retreating to more shaded conditions in refuges under bushes, or by shifting to full shade or down mammal burrows (Kerr et al. 2003). In the model, when the potential temperature of a retreated lizard at the shallowest depth in the sun did not exceed $39^{\circ} \mathrm{C}$, the lizard was simulated to shelter in this location (simulating sunny retreats). Otherwise, the simulated lizard chose refuges with maximum $(50 \%)$ shade, using the shallowest depth initially and moving deeper (and thus into less extreme temperature conditions) if body temperature either dropped to the critical thermal minimum $\left(\mathrm{CT}_{\min }\right)$ or rose above $39^{\circ} \mathrm{C}$. The lizards were also simulated to move deeper underground (to $60 \mathrm{~cm}$ ) if they became desiccated to a threshold proportion of their normal wet mass. This simulated the empirically observed use by the sleepy lizard of deep burrows in hot and dry conditions (Kerr and Bull 2006b). Using these behavioral assumptions, the ectotherm model predicted when lizards should be active in each day, and the body temperature and hydric balance achieved at each hour of each day.

Biophysical simulations were run with and without the Dynamic Energy Budget model (see Dynamic energy budget model), the latter simulations capturing overall thermal constraints on activity by predicting all times when activity would be possible, the former (DEB) simulations capturing internal (metabolic) constraints on activity by inducing activity only when required to balance the energy budget.

\section{Simulating water loss}

The avenues for water loss in a lizard include the skin and eyes (cutaneous water loss), the breath (respiratory water loss), as well as that lost in feces and urine (Pirtle et al., in press). Cutaneous water loss depends on the vapor pressure deficit of the environment, the mass transfer coefficient and the fraction of the total area of the animal that can be conceived as a free water surface, $F_{\text {wet }}$ (Tracy 1976, Kearney and Porter 2004). The latter parameter was estimated from total evaporative water loss data following the methods described in Appendix D of Kearney and Porter (2004). The observed water loss rate data came from Warburg (1965) for T. rugosa held at $2.5 \%$ relative humidity and temperatures of $25^{\circ} \mathrm{C}, 30^{\circ} \mathrm{C}, 35^{\circ} \mathrm{C}$, and $37.5^{\circ} \mathrm{C}$ for durations of 2,8 , and $24 \mathrm{~h}$. Respiratory water loss was predicted from Wilson's (1974) $\mathrm{O}_{2}$ consumption rate data assuming an oxygen extraction efficiency of $16 \%$ (Bennett 1973). For these calculations, respiration data from Wilson (1974) was interpolated with a power function from a $461 \mathrm{~g}$ animal to that of a $351 \mathrm{~g}$ animal as used in Warburg (1965). Surface area was computed based on that of the desert iguana (Porter et al. 1973; see Table 1). Non-respiratory evaporative water loss was partitioned into cutaneous and ocular, assuming the eyes were open during the measurements and that they made up $0.03 \%$ of the total surface area (the latter approximated from photographs). Biophysical simulations of water loss rates were made under the assumption that eyes were open

TABLE 1. Ectotherm model parameters for Tiliqua rugosa.

\begin{tabular}{|c|c|c|c|}
\hline Parameter & Units & Value & Source \\
\hline$\varepsilon_{\text {body }}$, skin longwave infrared emissivity & & 1.0 & default \\
\hline$\alpha_{\text {body }}$, skin solar absorptivity & & 0.866 & Christian et al. (1996) \\
\hline$\rho_{\text {body }}$, flesh density & $\mathrm{kg} \mathrm{m}^{3}$ & 1000 & default \\
\hline$k_{\text {body }}$, flesh thermal conductivity & $\mathrm{W} \cdot \mathrm{m}^{-1} \cdot{ }^{\circ} \mathrm{C}^{-1}$ & 0.5 & default \\
\hline$F_{\text {body,sky, }}$ configuration factor body to sky & & 0.4 & Porter et al. (1973) \\
\hline$F_{\text {body,sub}}$, configuration factor body to substrate & & 0.4 & Porter et al. (1973) \\
\hline$A$, lizard surface area & $\mathrm{cm}^{2}$ & $10.4713 W_{w}^{0.688}$ & Porter et al. (1973) \\
\hline$A_{\text {sil }}$, silhouette area normal to the sun & $\mathrm{cm}^{2}$ & $3.798 W_{w}^{0.683}$ & Porter et al. (1973) \\
\hline$F_{\text {sub }}$, fraction of surface area contacting the substrate & & $0.1 \quad w$ & assumed \\
\hline$F_{\text {wet }}$, fraction of surface area that is wet & & 0.0037 & Warburg (1965) \\
\hline$T_{\mathrm{RB}}^{\min }$, minimum temperature for leaving retreat & ${ }^{\circ} \mathrm{C}$ & 8.5 & Kerr and Bull (2004) \\
\hline$T_{\mathrm{F}}^{\min }$, minimum foraging temperature & ${ }^{\circ} \mathrm{C}$ & 26.0 & Pamula (1997: Fig. 3.42) \\
\hline$T_{\mathrm{F}}^{\max }$, maximum foraging temperature & ${ }^{\circ} \mathrm{C}$ & 39.0 & Pamula (1997: Fig. 3.42) \\
\hline$T_{\text {pref }}$, preferred temperature & ${ }^{\circ} \mathrm{C}$ & 33.5 & Pamula (1997: Table 3.14) \\
\hline $\mathrm{CT}_{\text {min }}$, critical thermal minimum & ${ }^{\circ} \mathrm{C}$ & 3.5 & Bennett and John-Alder (1986) \\
\hline
\end{tabular}

Notes: $W_{\mathrm{w}}$ is wet mass in grams. Empty cells indicate that the parameter is unitless. 
only during activity. The remaining avenues of water exchange, that is, water losses through feces and urine, and water gains through food and metabolic water, were driven by the DEB model, assuming $73 \%$ fecal water as measured for a related herbivorous species (Shine 1971) and that no urinary water was produced (Bentley 1959b). We did not explicitly model the electrolyte metabolism of this species, although it has been shown to tolerate excessive serum sodium levels (Bentley 1959a,b).

\section{Simulating burrow environments}

Burrow environments have lower water vapor pressure deficits (the difference between vapor pressure of air relative to that at saturation) and are more thermally buffered than aboveground conditions (Schmidt-Nielsen and SchmidtNielsen 1950, Shimmin et al. 2002). Humidity can be near saturation in soil pore spaces or closed chambers, even at very low soil moisture content (Schmidt-Nielsen and Schmidt-Nielsen 1950, Campbell and Norman 1998, Moore et al. 2018). However, burrow humidity will depend on the depth and distance from the burrow entrance as well as the degree of ventilation of the burrow (Shimmin et al. 2002). The NicheMapR microclimate model computes site-specific soil humidity given soil moisture predictions (Kearney and Porter 2017, Kearney and Maino 2018). To estimate burrow humidity, we computed a weighted mean of ambient $(1 \mathrm{~cm}$ above ground) and soil vapor pressure whereby the fractional weighting to soil vapor pressure increased linearly with soil depth from 0 to 0.9 , in 0.1 increments. Because soil spacing for the model is logarithmic (closer near the surface), this resulted in a weighting function to soil vapor pressure of $w=0.1578 \ln (D)+0.0596$, where $D$ is depth in centimeters. We tested this method against detailed observations of burrow vapor pressure (and temperature) for the great desert skink Liopholis kintorei across one year at Newhaven Sanctuary $\left(22.72^{\circ} \mathrm{S}, 131.17^{\circ} \mathrm{E}\right)$, a site in arid central Australia (Moore et al. 2018). All sheltering lizards were assumed to experience low $(0.01 \mathrm{~m} / \mathrm{s})$ wind speed.

\section{Dynamic energy budget model}

The ecotherm model of NicheMapR includes an implementation of the standard Dynamic Energy Budget (DEB) model, which predicts the trajectory of development, growth and reproduction as a function of body temperature and food intake. It also includes a full mass budget that integrates with the ectotherm heat budget model in NicheMapR to compute water balance (Kearney et al. 2013).

We estimated the parameters of the "standard" dynamic energy budget model for the sleepy lizard using the "covariation method" (Lika et al. 2011a, b, Marques et al. 2018), based on parameters derived from the detailed observations of growth and reproduction from the ongoing captive colony previously described. In addition to the single-observation ("zero-variate") data (Table 2), we included univariate data on length vs. age ( $n=14$ individuals), mass vs. age $(n=8)$, and length vs. mass $(n=33)$ derived from the captive colony. The data on growth and reproduction from the captive colony were necessarily collected under daily and seasonal variation in body temperature, since this species does poorly under constant temperature. To implement an appropriate temperature correction for rates, we used records of available body temperatures throughout the day and across the year in the captive facility as part of the estimation procedure. Finally, we included observations of resting oxygen consumption rate at body temperatures ranging from $8^{\circ} \mathrm{C}$ to $41.5^{\circ} \mathrm{C}$ (Wilson 1974). Female individuals were used for all observations except oxygen consumption rate and mass/length at birth, where sex was unknown. The associated MATLAB scripts used to estimate these parameters can be found online. ${ }^{10}$

Preliminary simulations suggested that the DEB model was overestimating mass loss in terms of reserve (rather than water) during desiccation-induced estivation events. We therefore incorporated the potential for lizards to depress their metabolism during estivation, as has been observed in a variety of lizards (reviewed in Christian et al. 1999). To achieve this, we altered the DEB model equations by a depression fraction that acted on all rate parameters, that is, specific somatic $\left[\dot{p}_{\mathrm{m}}\right]$ and maturity maintenance $\dot{k}_{\mathrm{j}}$, energy conductance $\dot{v}$, maximum specific assimilation $\left\{\dot{p}_{\mathrm{Am}}\right\}$, and aging acceleration $\ddot{\mathrm{a}}$. We adjusted this depression factor to provide a match to the body mass data of Kerr and Bull (2004) (Fig. 9), resulting in a value of $46 \%$ (i.e., $54 \%$ depression) as compared to the mean value of $50 \%$ reported by Christian et al. (1999: Table 1) for a range of temperate and tropical lizard species.

\section{Thermal response function}

We used the five-parameter Arrhenius temperature correction method (Sharpe and DeMichele 1977) to adjust rates with body temperature. The Arrhenius temperature $T_{\mathrm{A}}(\mathrm{K})$ was determined as the grand mean value estimated from our own unpublished data on the thermal sensitivity of oxygen consumption rate for five related species (T. scincoides, Egernia cunninghami, Egernia striolata, Liopholis inornata, and Liopholis striata) as well as that based on Wilson's (1974) data, which were not statistically different from each other (grand mean $9625 \mathrm{~K}$, value for T. rugosa $9740 \mathrm{~K}$, based on Wilson [1974]). This corresponds to a $Q_{10}$ of 3 . We specified the upper and lower limits of the thermal tolerance range, $T_{\mathrm{L}}$ and $T_{\mathrm{H}}$, as the critical thermal minimum and maximum, respectively. We used a value of $20,000 \mathrm{~K}$ for the parameters $T_{\mathrm{AL}}$ and $T_{\mathrm{AH}}$, which control the rate of decrease of the thermal response curve; this provided a close approximation to the data of Wilson (1974) (Fig. 1a).

\section{Modeling food and its water content}

Sleepy lizards feed mainly on flowers, fruits, and certain palatable leaves of annual plants (Dubas and Bull 1991). Thus, food availability for the sleepy lizard is closely tied to plant growth, with lizards especially dependent on winterannual plants, which dry out and die by mid-summer at the study site as the near-surface soil dries (Kerr and Bull 2006b). Normally sleepy lizards in the study region do not have access to free water, and so rely on water in their food (but see Wright et al. 2013) and from rainfall. When modeling the energy and mass budget of the sleepy lizard, we

\footnotetext{
${ }^{10}$ https://github.com/mrke/Tiliqua_rugosa/DEBmodel
} 
TABLE 2. Dynamic energy budget (DEB) model parameter estimation of Tiliqua rugosa.

\begin{tabular}{|c|c|c|c|c|c|c|}
\hline Data or parameter & Observed & Predicted & MRE & Units & Value & Source \\
\hline \multicolumn{7}{|l|}{ (a) Observed and predicted data } \\
\hline$a_{\mathrm{b}}$, age at birth & 150.0 & 173.1 & 0.154 & $\mathrm{~d}$ & & \\
\hline$a_{\mathrm{p}}$, age at puberty & 547.5 & 433.8 & 0.208 & $\mathrm{~d}$ & & \\
\hline$a_{\mathrm{m}}$, longevity & 50 & 50 & $8.4 \times 10^{-6}$ & $\mathrm{yr}$ & & \\
\hline$l_{\mathrm{b}}$, length at birth & 16.5 & 15.8 & 0.040 & $\mathrm{~cm}$ & & \\
\hline$l_{\mathrm{p}}$, length at puberty & 23 & 21.3 & 0.074 & $\mathrm{~cm}$ & & \\
\hline$l_{\infty}$, maximum length & 32.8 & 33.1 & 0.008 & $\mathrm{~cm}$ & & \\
\hline$W_{\mathrm{b}}$, mass at birth & 99 & 93 & 0.058 & $\mathrm{~g}$, wet & & \\
\hline$W_{\mathrm{p}}$, mass at puberty & 180 & 227 & 0.261 & $\mathrm{~g}$, wet & & \\
\hline$W_{\infty}$, maximum mass & 717 & 850 & 0.186 & $\mathrm{~g}$, wet & & \\
\hline$R_{\infty}$, maximum reproduction rate & 1.7 & 1.7 & 0.005 & no./yr & & \\
\hline \multicolumn{7}{|l|}{ (b) DEB parameters } \\
\hline$z$, zoom factor (relative volumetric length) & & & & & 7.262 & estimated \\
\hline$\delta_{\mathrm{M}}$, shape correction factor & & & & & 0.220 & estimated \\
\hline$\dot{v}$, energy conductance & & & & $\mathrm{cm} / \mathrm{d}$ & 0.048 & estimated \\
\hline$\kappa$, allocation fraction to soma & & & & & 0.81 & estimated \\
\hline$\left[\dot{p}_{\mathrm{M}}\right]$, somatic maintenance & & & & $\mathrm{J} \cdot \mathrm{cm}^{-3} \cdot \mathrm{d}^{-1}$ & 45.1 & estimated \\
\hline$\left[E_{\mathrm{G}}\right]$, cost of structure & & & & $\mathrm{J} / \mathrm{cm}^{3}$ & 7814 & estimated \\
\hline$k_{\mathrm{j}}$, maturity maintenance rate coefficient & & & & $\mathrm{d}^{-1}$ & 0.002 & default \\
\hline & & & & $\mathrm{J}$ & $1.008 \times 10^{5}$ & estimated \\
\hline \multicolumn{7}{|l|}{$E_{\mathrm{H}}^{\mathrm{b}}$, maturity at birth } \\
\hline \multicolumn{6}{|l|}{$E_{\mathrm{H}}^{\mathrm{p}}$, maturity at puberty } & estimated \\
\hline$\ddot{h_{\mathrm{a}}}$, Weibull aging acceleration & & & & $\mathrm{d}^{-2}$ & $3.13 \times 10^{-11}$ & estimated \\
\hline$\kappa_{\mathrm{R}}$, reproduction efficiency & & & & & 0.95 & default \\
\hline$E_{0}$, energy content of "egg", & & & & $\mathrm{J}$ & $9.59 \times 10^{5}$ & estimated \\
\hline & & & & $\mathrm{J} / \mathrm{cm}^{3}$ & 738 & Barwick (1965) \\
\hline \multicolumn{7}{|l|}{$\left[E_{\mathrm{s}}^{\mathrm{m}}\right]$, maximum specific stomach energy } \\
\hline$\kappa_{X}$, digestion efficiency & & & & & 0.85 & Shine (1971) \\
\hline$\left\{\dot{p}_{\mathrm{Xm}}\right\}$, maximum specific food intake & & & & $\mathrm{J} \cdot \mathrm{cm}^{-2} \cdot \mathrm{d}^{-1}$ & 164,387 & $\begin{array}{l}\text { Dubas and } \\
\text { Bull (1991) }\end{array}$ \\
\hline$K$, half saturation constant & & & & $\mathrm{J} / \mathrm{cm}^{2}$ & 1.60 & $\begin{array}{c}\text { Dubas and } \\
\text { Bull (1991) }\end{array}$ \\
\hline$X$, food density & & & & $\mathrm{J} / \mathrm{cm}^{2}$ & 14.2 & $\begin{array}{c}\text { Dubas and } \\
\text { Bull (1991) }\end{array}$ \\
\hline$d_{\mathrm{V}}$, density of structure & & & & $\mathrm{g} / \mathrm{cm}^{3}$ & 0.3 & assumed \\
\hline$W_{\mathrm{V}}$, molecular weight of structure & & & & $\mathrm{g} \mathrm{C} / \mathrm{mol}$ & 23.9 & default \\
\hline$\mu_{\mathrm{X}}$, chemical potential of food & & & & $\mathrm{J} \mathrm{C} / \mathrm{mol}$ & 525,000 & default \\
\hline$\mu_{\mathrm{E}}$, chemical potential of reserve & & & & $\mathrm{J} \mathrm{C} / \mathrm{mol}$ & 585,000 & default \\
\hline$\mu_{\mathrm{V}}$, chemical potential of structure & & & & $\mathrm{J} \mathrm{C} / \mathrm{mol}$ & 500,000 & default \\
\hline$\mu_{\mathrm{p}}$, chemical potential of feces & & & & $\mathrm{J} \mathrm{C} / \mathrm{mol}$ & 480,000 & default \\
\hline$\kappa_{\mathrm{XP}}$, fraction of food energy into feces & & & & & 0.1 & default \\
\hline$T_{\mathrm{A}}$, Arrhenius temperature & & & & $\mathrm{K}$ & 9625 & observed \\
\hline$T_{\mathrm{L}}$, lower bound for $T_{\mathrm{A}}$ & & & & $\mathrm{K}$ & 288 & matched to $\mathrm{CT}_{\min }$ \\
\hline$T_{\mathrm{H}}$, upper bound for $T_{\mathrm{A}}$ & & & & $\mathrm{K}$ & 315 & matched to $\mathrm{CT}_{\max }$ \\
\hline$T_{\mathrm{AL}}$, value of $T_{\mathrm{A}}$ below lower bound & & & & $\mathrm{K}$ & 20,000 & estimated \\
\hline$T_{\mathrm{AH}}$, value of $T_{\mathrm{A}}$ above upper bound & & & & $\mathrm{K}$ & 20,000 & estimated \\
\hline
\end{tabular}

Notes: Part a shows the observed and the predicted "zero-variate" data (all observations from the present study) and mean relative error (MRE) and part $b$ shows the core dynamic energy budget (DEB) parameter estimates (rates corrected to $20^{\circ} \mathrm{C}$ ), and additional DEB parameters either independently observed or assumed to have default values. The lengths relate to snout-vent length (SVL).

assumed that the moisture content of the food varied as a function of soil moisture (computed as described later in this section). We assumed that the lizards had access to suitable food plants at all times, with the plants' nutritional value changing with moisture content only. The feeding rate was thus limited by handling rather than searching time, as determined by DEB model feeding dynamics, which integrate the thermal rate responses of feeding, digestion and maintenance costs, as well as whether the lizard was simulated to be active.
The feeding process in DEB theory depends on the food density per ground surface area $X\left(\mathrm{~J} / \mathrm{cm}^{2}\right)$, the maximum feeding rate per structural surface area $\left\{\dot{p}_{\mathrm{Xm}}\right\}\left(\mathrm{J} \cdot \mathrm{cm}^{-2} \cdot \mathrm{h}^{-1}\right)$, the half-saturation constant $K\left(\mathrm{~J} / \mathrm{cm}^{2}\right)$, and the maximum stomach energy capacity $\left[E_{\mathrm{s}}^{\mathrm{m}}\right]$ (Kooijman 2010:32 and 267, Kearney et al. 2013). Food density was assumed to be $14.2 \mathrm{~J} / \mathrm{cm}^{2}$ based on Dubas and Bull's (1991) observation of 200 Tetragonia sp. berries $/ \mathrm{m}^{2}$ of plant area and a berry radius of $0.35 \mathrm{~cm}$, with an assumed energy content of 

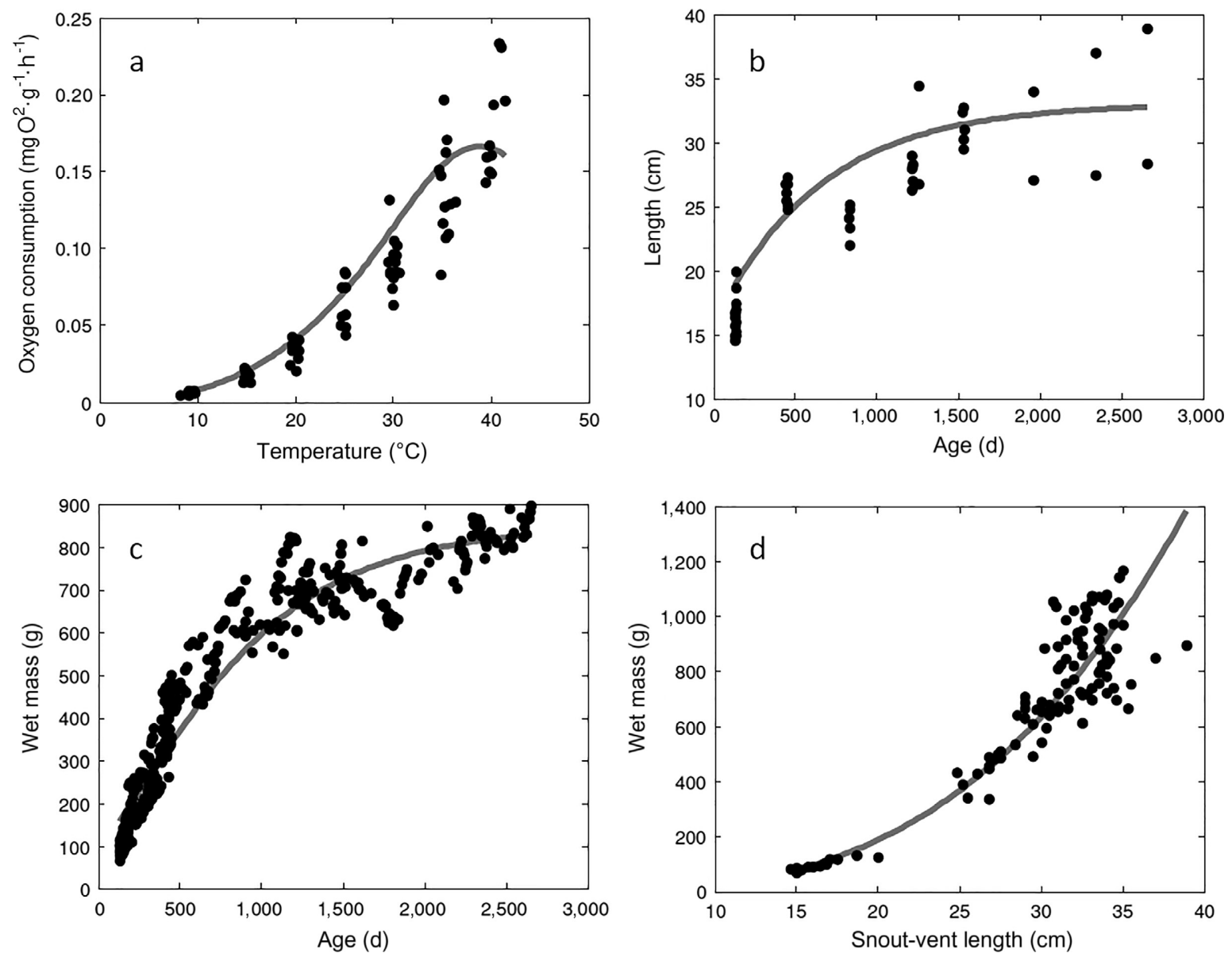

FIG. 1. Dynamic energy budget model fits (gray lines) to observations (black dots) of (a) oxygen consumption vs. temperature, (b) length vs. time, (c) mass vs. time, and (d) mass vs. length.

3,970 J/g (Brand-Miller and Holt 1998) and density of $1 \mathrm{~g} / \mathrm{cm}^{3}$. Stomach volume was assumed to be $10 \%$ of total body mass based on data for a related herbivorous lizard (Barwick 1965). Maximum food intake rate and the half saturation constant were based on an observed mean daily feeding time of 13.5 min (Dubas and Bull 1991), assuming that the stomach volume was filled in this time and that the animal was at the preferred $T_{\mathrm{b}}$ of $33.5^{\circ} \mathrm{C}$ (Pamula 1997) when feeding (note that reported rate parameter inputs are all corrected to a reference temperature of $20^{\circ} \mathrm{C}$ ).

We used soil moisture and water potential estimates at $10 \mathrm{~cm}$ depth, derived from the microclimate model, to estimate plant availability and plant moisture content. We assumed maximum plant moisture content $(82 \%)$ at soil water potential above $-200 \mathrm{~J} / \mathrm{kg}$ (a typical value below which some temporary wilting will occur in crop plants) and a linearly declining moisture content as soil water potential dropped toward the permanent wilting point $(-1,500 \mathrm{~J} / \mathrm{kg}$; Campbell and Norman 1998), where we assumed no moisture was available in plant matter. Plants required a consecutive 14-d recovery period with conditions above this threshold to recover (i.e., to regerminate from seed). These calculations were encoded in the function plantgro that is included in the NicheMapR package. On days with rainfall above $3.5 \mathrm{~mm}$, dehydrated lizards were simulated to fully hydrate by drinking, for example, from surface water or by ingesting hydrated thalli of the cyanobacterium Nostoc (Kerr and Bull 2004). The threshold of $3.5 \mathrm{~mm}$ rainfall was based on observed responses of body condition to rainfall (Kerr and Bull 2004; see Fig. 9).

\section{Life cycle and distribution limit simulations}

Whole life cycle simulations of the integrated biophysical/ DEB model were run for the Bundey Bore site from 1991 to 2010, starting the lizard as a newborn in the autumn (day 90) of the first year. Reproduction was simulated to start on the vernal equinox (mobilization of reproduction buffer to egg batch) and, once sufficient energy for a clutch accumulated, embryonic development was initiated. Ovoviviparity was assumed and the developing embryo experienced the body temperature of a thermoregulating mother (see Schwarzkopf et al. [2016] for more details on modeling viviparity with DEB theory). Clutch size was simulated to vary from one to two as a linear function of snout-vent length, with the transition occurring at $31.8 \mathrm{~cm}$ based on Pamula (1997).

Hourly predicted body temperature, activity state, and body condition/hydric state were summarized and compared with the empirical data for the state reached over the years 2002-2003 and 2009-2010 (when detailed empirical data 
were available). We also compared observed and predicted growth trajectories in terms of length and mass from the mark-recapture data previously described against simulations at the site over longer periods (1983-2013). Ages of the observed lizards were unknown so these simulations were run with different starting dates and different starting states (hatchling, adult) to find the best alignment with the observed trajectory of each of the 29 individuals. To account for individual variation in maximum size in the latter analyses, the zoom factor $z$ was altered by the proportional difference between the observed maximum length (in the second half of an individual's time series) and the maximum length $(33 \mathrm{~cm})$ implied by the estimated DEB parameters (see Kearney 2012 for further explanation). The reproduction buffer was subtracted from the total wet mass for comparisons to observed mass for male individuals. Simulations were run assuming water intake was rain- and food-limited, or assuming the lizard had access to permanent water. In the latter simulations, the energy and mass budget dynamics were controlled only by thermal environmental constraints.

To assess the model's ability to capture distribution limits, we ran the model for the years 1990-2009 across 1,900 locations spread evenly across the Australian continent. Twenty replicate simulations were run per site, systematically varying the start year to capture cohort effects (and looping around to add on preceding years, thus maintaining $20 \mathrm{yr}$ simulations). The outputs from the simulations included, for each cohort, the annual activity time, retreat site depths chosen, desiccation levels, size (length and mass) attained, reproductive timing, number of offspring, and survival. In an initial run, the simulations were started on the 90th day of the year to replicate the typical pattern of autumn parturition (Bull et al. 1993). The circular mean of the parturition dates was then computed per pixel over all cohort runs and used as a base map to determine the start day of a second and final simulation. The simulations were repeated for six climate change scenarios for 2070, described in Briscoe et al. (2016), imposed on the 1990-2009 daily weather grids. The starting date of all climate change simulations was based on the parturition dates for a preliminary run of the ACCESS 1.3 climate change scenario.

As described in Kearney (2012), age-specific fecundity and survival values were used to compute the finite rate of increase $R_{0}$. Survival due to environmental conditions (heat/ cold stress, desiccation, starvation) was explicit in the model, with simulations terminating upon death. To implicitly include mortality due to predation, an hourly mortality rate of $6.7 \times 10^{-5}$ for active individuals was used based on Jones et al. (2016)'s estimate of annual survival during climatically favorable years of 0.915 , and a mean annual activity time of $1,317 \mathrm{~h}$ (from this study) at the study site. Inactive animals were assumed to have no risk of predation.

Unless stated otherwise, all analyses were performed in the $\mathrm{R}$ environment ( $\mathrm{R}$ Development Core Team 2012).

\section{RESULTS}

\section{Dynamic energy budget model}

We estimated DEB parameters (Table 2b) for the sleepy lizard with a mean relative error $(\mathrm{MRE})=$ $\sqrt{\left(1-\frac{\text { observed value }}{\text { expected value }}\right)^{2}}$ of 0.114 across "zero-variate" (Table 2a) and univariate (Fig. 1) data. The largest disparities between observed and predicted values occurred for wet mass at puberty, age at puberty, and oxygen consumption rate $(\sim 0.2-0.26 \mathrm{MRE})$, with all other observations having a MRE of $\sim 0.18$ or lower.

\section{Weather, soil temperature, and burrow microclimate predictions}

The microclimate model, when driven by the daily gridded weather data, reconstructed the hourly $1.2 \mathrm{~m}$ air temperature $\left(r=0.95\right.$, root mean square error $\left.[\mathrm{RMSE}]=2.8^{\circ} \mathrm{C}\right)$ and solar radiation $\left(r=0.97, \mathrm{RMSE}=82.6 \mathrm{~W} / \mathrm{m}^{2}\right)$ at Newhaven Sanctuary with high accuracy. Relative humidity $(r=0.78, \quad \mathrm{RMSE}=13.9 \%)$ and wind speed $(r=0.52$, $\mathrm{RMSE}=1.4 \mathrm{~m} / \mathrm{s}$ ) were also adequately predicted (Appendix S1: Fig. S1). The integration of this input weather data and the soil and terrain data produced highly accurate predictions of soil temperature at the surface $(r=0.95$, $\left.\operatorname{RMSE}=5.0^{\circ} \mathrm{C}\right), 5 \mathrm{~cm}\left(r=0.96, \quad \operatorname{RMSE}=3.8^{\circ} \mathrm{C}\right), 10 \mathrm{~cm}$ $\left(r=0.95, \mathrm{RMSE}=2.8^{\circ} \mathrm{C}\right), 30 \mathrm{~cm}\left(r=0.97, \mathrm{RMSE}=2.2^{\circ} \mathrm{C}\right)$, $50 \mathrm{~cm}\left(r=0.98, \operatorname{RMSE}=1.8^{\circ} \mathrm{C}\right)$, and $100 \mathrm{~cm} \quad(r=0.96$, $\mathrm{RMSE}=2.4^{\circ} \mathrm{C}$; Appendix S1: Fig. S2).

Burrow temperature and humidity were measured at three depth categories ranging $5-15 \mathrm{~cm}, 30-50 \mathrm{~cm}$, and 50 $100 \mathrm{~cm}$. The best fit between mean observed burrow temperature and predicted temperature was for the simulated depths of $10 \mathrm{~cm}\left(r=0.95, \quad \mathrm{RMSE}=2.5^{\circ} \mathrm{C}\right), \quad 50 \mathrm{~cm} \quad(r=0.98$, $\left.\operatorname{RMSE}=1.6^{\circ} \mathrm{C}\right)$, and $100 \mathrm{~cm} \quad\left(r=0.98, \operatorname{RMSE}=1.5^{\circ} \mathrm{C}\right.$; Fig. 2a, c, e). At these depths, observed vapor pressure deficit (VPD) was well predicted by the weighted mean (Methods) of the simulated ambient (surface) and soil VPD $(10 \mathrm{~cm}, r=0.85$, RMSE $0.92 \mathrm{kPa} ; 50 \mathrm{~cm}, r=0.76$, $\mathrm{RMSE}=0.48 \mathrm{kPa} ; 100 \mathrm{~cm}, r=0.80, \quad \mathrm{RMSE}=0.41 \mathrm{kPa}$; Fig. 2b, d, f).

\section{Observed and predicted body temperature and activity}

Recorded body surface temperatures for the 61 sleepy lizards in the spring/summer of 2009 and 2010 at the field site ranged from $2.8^{\circ} \mathrm{C}$ to $48.4^{\circ} \mathrm{C}$, with most $(90 \%)$ between $9.8^{\circ} \mathrm{C}$ and $34.5^{\circ} \mathrm{C}$ (Fig. 3). The movement rates showed a classic thermal response curve, peaking at around the preferred temperature of $33.5^{\circ} \mathrm{C}$ (Fig. 4a), and closely followed the Arrhenius thermal response curve fitted to the metabolic rate data (Fig. 4b). Our simulation of a thermoregulating lizard at the site accurately captured the hourly body temperature fluctuations experienced by those lizards (Fig. 3, summary plots for individual lizards in Appendix S2). The RMSE was $3.9^{\circ} \mathrm{C}$ (range $2.9-5.6^{\circ} \mathrm{C}$ ), which was $\approx 10 \%$ of the observed range of values, and correlation coefficients between observed and predicted temperatures averaged 0.91 across all lizards (range 0.81-0.96).

Pooling across all individuals (to obtain all hours where at least one individual was active), lizards were active for between 0 and $8 \mathrm{~h}$ on any given day, with the mean seasonal and daily patterns of activity broadly captured by the model (Fig. 5a). The model correctly assigned activity state (moving or not moving) for $84 \%$ of individual-level observation 

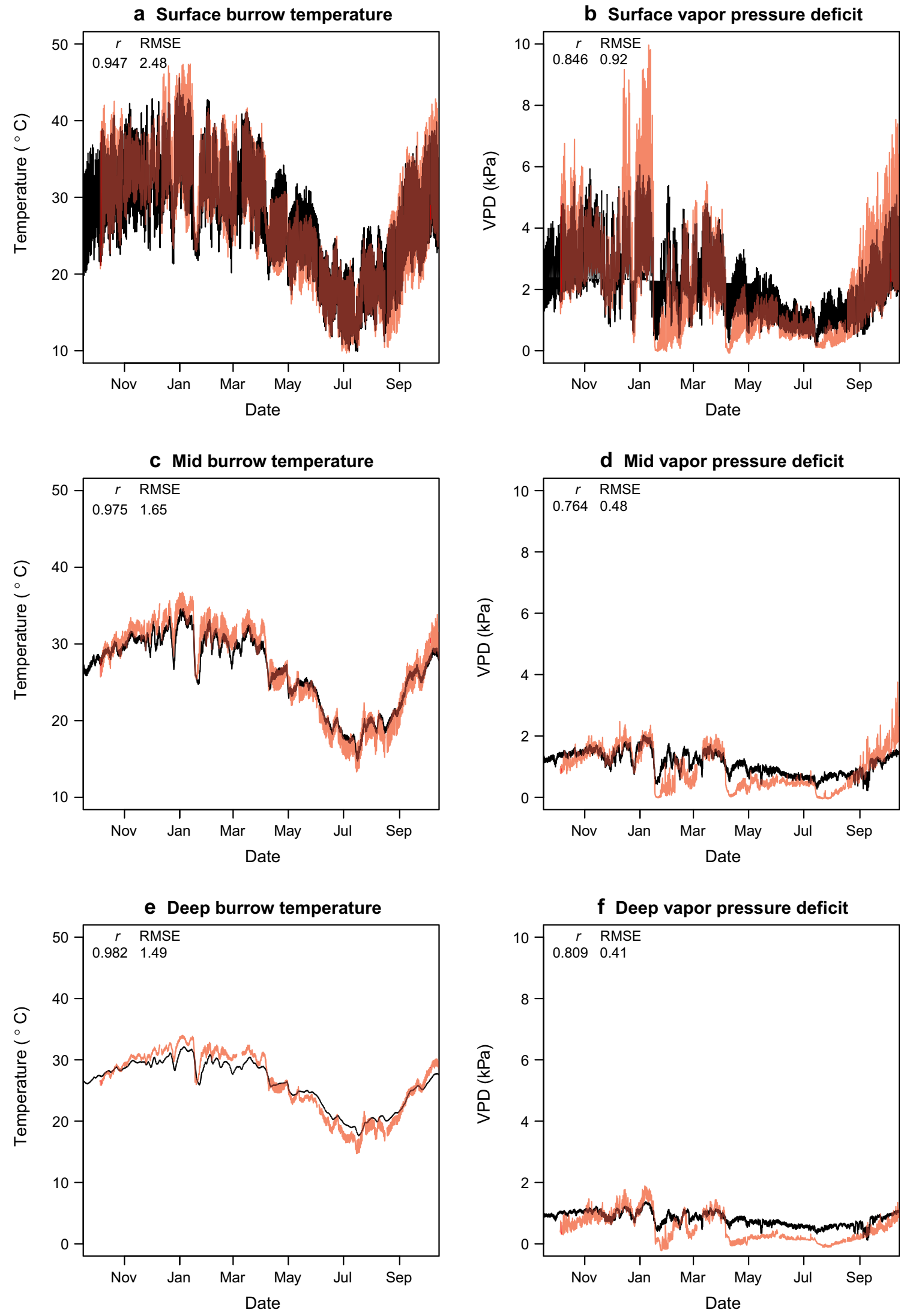

FIG. 2. Observed (red) and predicted (black) temperature and humidity (vapor pressure deficit, VPD) in burrows of great desert skinks over a one-year period in 2014 at Newhaven Sanctuary, central Australia $\left(22.72^{\circ} \mathrm{S}, 131.17^{\circ} \mathrm{E}\right)$. The depths of the surface, mid, and deep burrows were 10,50 , and $100 \mathrm{~cm}$, respectively. 
a Observed and predicted temperature vs. time, 2009

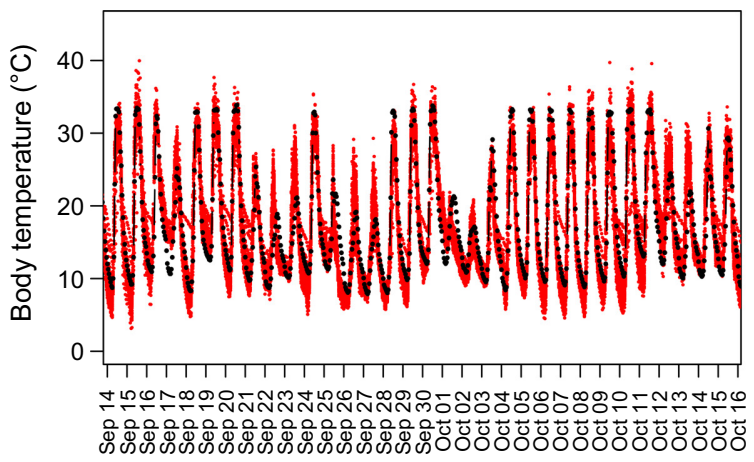

C Observed and predicted temperature vs. time, 2010

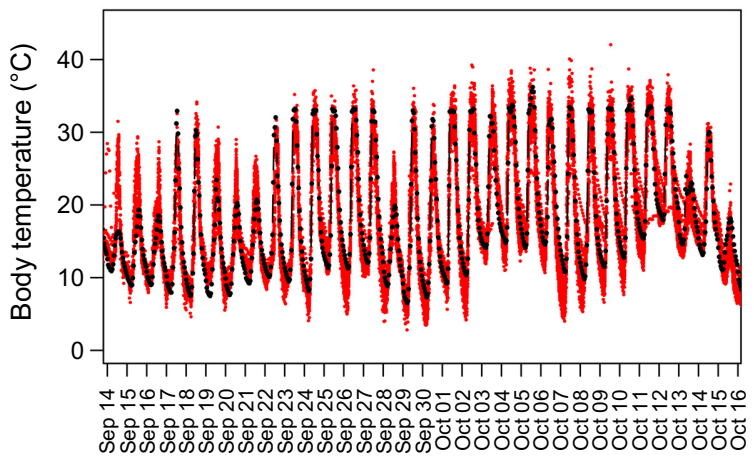

b Observed vs. predicted body temperature, 2009

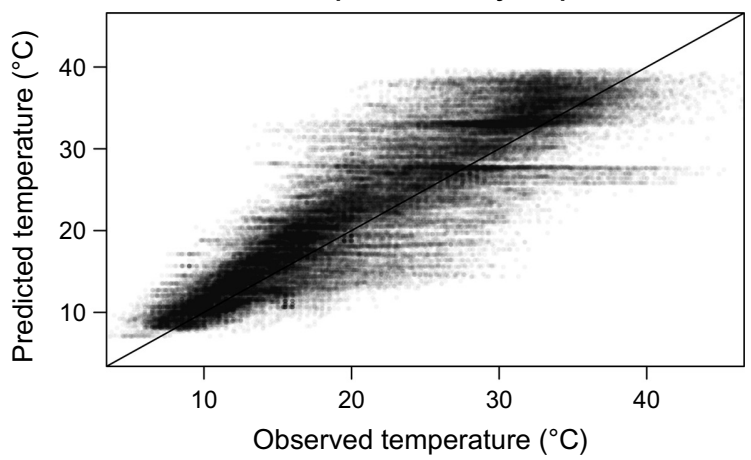

d Observed vs. predicted body temperature, 2010

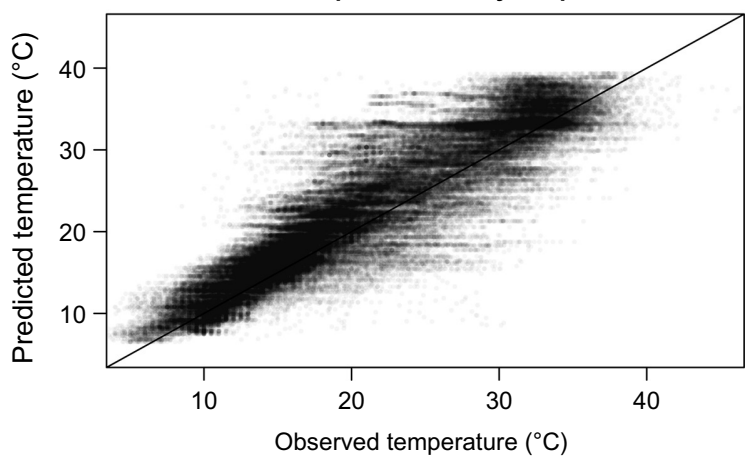

FIG. 3. (a, c) Two-minute observations of lizard body temperatures (red) and hourly predicted values (black) for one month in September-October 2009 and 2010 and (b, d) observed vs. predicted values across the entire study period of September to December. The straight lines in panels $\mathrm{b}$ and $\mathrm{d}$ indicate $1: 1$.
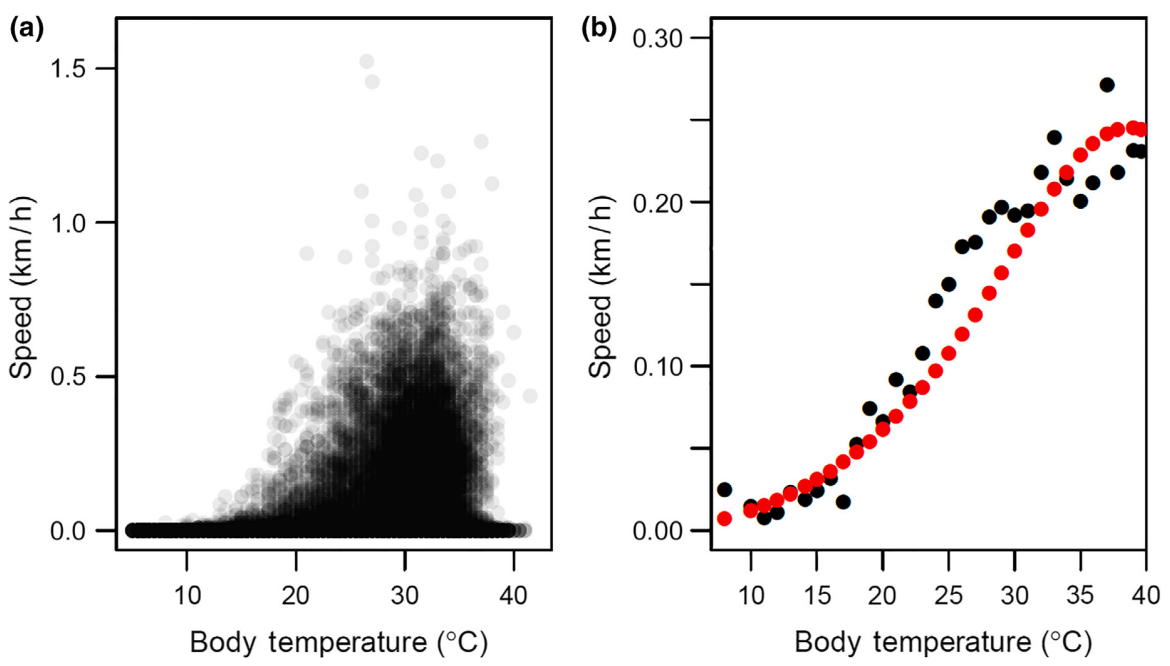

FIG. 4. (a) Movement rate values (computed from step counts using the equations in Kerr et al. [2004]) for all lizards tracked at the Bundey Bore site in 2009 and 2010 as a function of body temperature as estimated by on-board data loggers. (b) Also shown is the mean movement rate aggregated for each degree increment compared to that predicted by the Arrhenius thermal response parameters (Table 2) originally derived from the thermal response of oxygen consumption rate.

hours (range $76-89 \%$ ) when considering the $24 \mathrm{~h}$ day, and $71 \%$ of these observation hours (range $61-78 \%$ ) when considering daylight hours only. On average, $13 \%$ of the predicted daytime active values were false negatives (lizard moved when not predicted to) while $21 \%$ were false positives (lizard remained in its refuge when predicted to move).

\section{Temperature- and water-driven activity responses}

From late October, the model predicted frequent midday constraints on activity due to high temperature (Figs. 5, 6b, d). Cool conditions were predicted to limit early morning and late afternoon activity on most days, the limit declining 

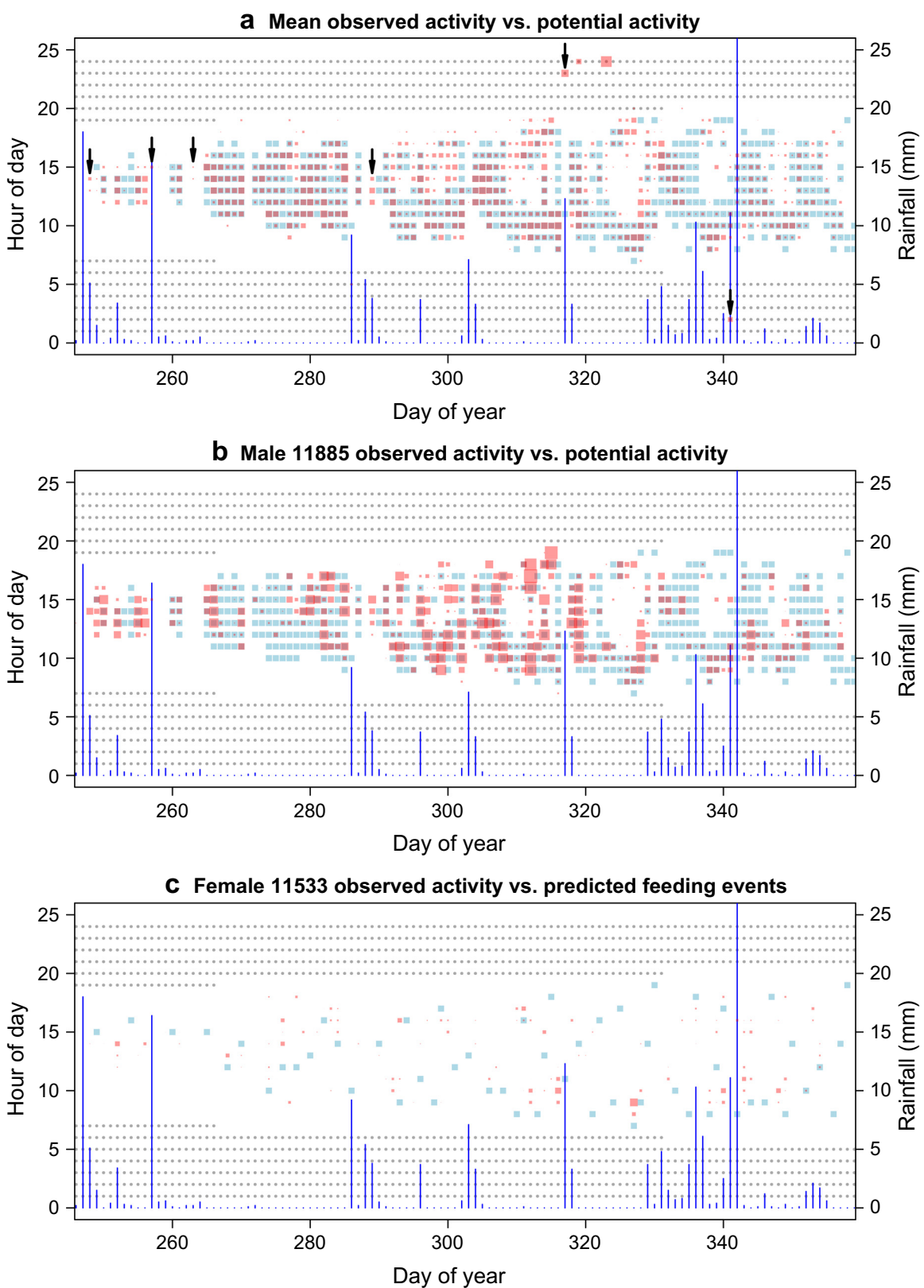

FIG. 5. Observed (red) and predicted (blue) activity across September-December 2010 for (a) lizards on average and (b, c) two individuals exhibiting strong contrasts in observed movement rate. In panel c, only the hours when the dynamic energy budget model calculations predicted feeding (when the stomach became $75 \%$ full) are indicated, whereas in panels a and $b$, all hours of thermally suitable foraging time are presented. The observed activity values are proportional to hourly summations of step counts. The gray dots indicate night-time hours while the vertical blue lines indicate rainfall events $(\mathrm{mm}$ rain/d). Black arrows indicate periods when lizards were active in colder-thanexpected conditions during rainfall events.

into the summer, and with some days predicted to be too cold for any activity (Figs. 5, 6b, d). These predictions were generally consistent with the observed patterns of activity and inactivity of the lizards (Figs. 5, 6b, d). However, during some rainfall events, lizards were active under conditions that were predicted to be too cool for activity, including some nocturnal foraging (indicated by arrows on Fig. 5a), as previously observed (Kerr and Bull 2004).

Most significantly, there was an anomalous period during 2009 when the activity was strongly suppressed. Our two-weekly recaptures relied on lizards being out of deep refuges, with recapture success consistently around $80 \%$ in 2010 but dropping to $<40 \%$ during a dry spell between 10 and 21 November 2009 (Fig. 7). During this dry spell, 11 of the 21 lizards from which data were obtained showed substantially damped body temperatures, highly consistent with movement into burrows $60 \mathrm{~cm}$ below the ground (Fig. 6a; Appendix S2). Eight of the 21 individuals tracked over the dry period, however, remained active. The body temperatures recorded for these individuals were highly consistent with temperatures 


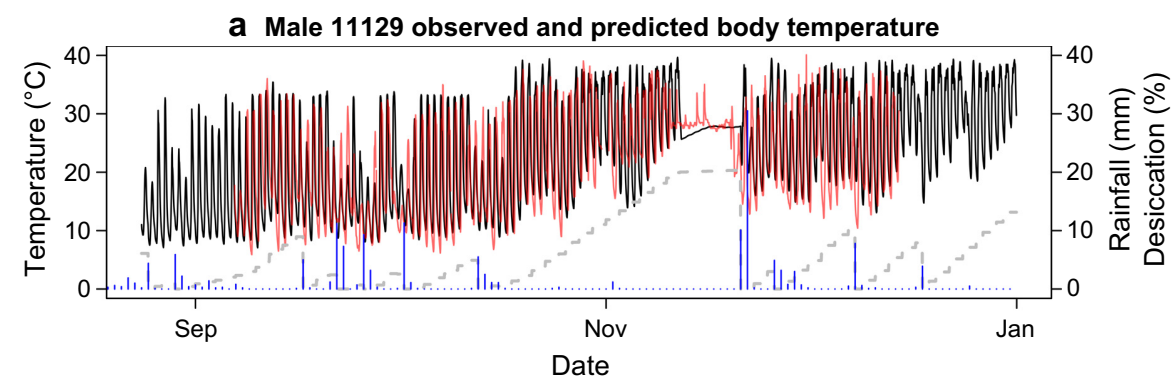

b Male 11129 observed and predicted activity
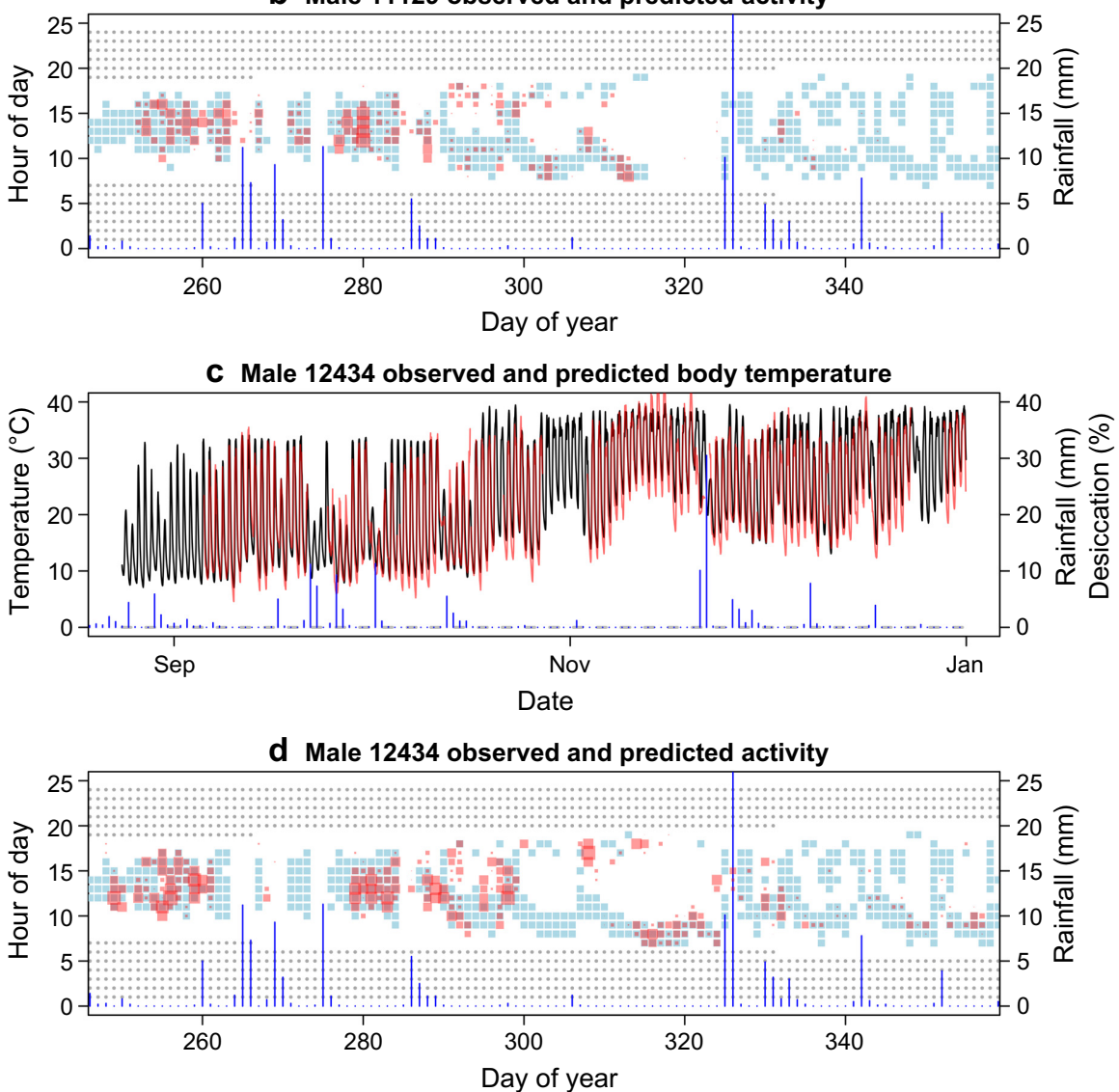

FIG. 6. (a, c) Observed (red) and predicted (black) body temperatures and (b, d) observed (red) and predicted (blue) activity patterns, that is, moving vs. not moving, for two contrasting lizards over September-December of 2009. The vertical blue lines indicate rainfall events $(\mathrm{mm} \mathrm{rain} / \mathrm{d})$ and the dashed gray line indicates predicted desiccation level (percentage of normal hydrated body mass). In the activity plots, observed values are proportional to hourly summations of step counts, the gray dots indicate nighttime hours, while black arrows indicate periods when lizards were active in colder-than-expected conditions during rainfall events. The simulation for lizard 11129 (a, b) assumes that water is only available via rainfall and food, while the simulation for lizard 12434 (c, d) assumes that drinking water is always available.

predicted by the model if they had remained aboveground (Fig. 6c-d; Appendix S2; the remaining two lizards showed limited activity and fluctuating body temperature).

The study site included a farm dam (standing water) and subsequent inspection of the movement patterns of the lizards as recorded by the GPS loggers indicated that those eight lizards remaining active during the dry spell had home ranges closer to this water body than those that became inactive (including those that could not be recaptured; Fig. 8). Moreover, activity of all lizards resumed immediately following a large rainfall event on 21 November 2009 (Fig. 6a-b; Appendix S2).

\section{Body condition and growth trajectories}

During the dry spell in 2009, the mean mass of 36 lizards for which data was available either side of the dry spell declined by $7 \%$ on average, with three individuals exceeding $20 \%$ declines (paired $t$ test, $t_{35}=5.30, P<0.001$ ). This difference was magnified when the individuals known to have remained active were excluded from the analysis $(10 \%$ decline, $\left.t_{27}=6.37, P<0.001\right)$, and the pattern disappeared when only the animals that remained active were compared ( $3 \%$ decline, $t_{7}=0.76, P=0.473$ ). Moreover, the correlation coefficient for predicted and observed mass averaged 0.41 


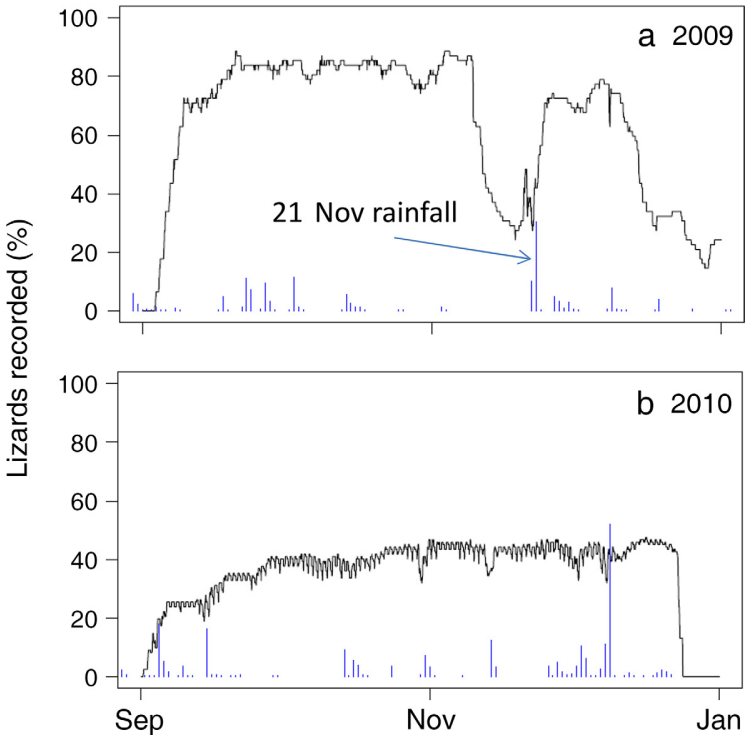

FIG. 7. The percentage captured in a given two-week period of the total number of lizards (a) 2009 and (b) 2010 at the Bundey Bore study site. Rainfall ( $\mathrm{mm}$ ) is also indicated by the blue vertical lines.

for 2009 but was -0.04 for 2010 , when there was no major dry spell (see Appendix S1 for all individual correlations).

Kerr and Bull (2004) observed strong declines in body mass $(\sim 20 \%)$ of between 10 and 20 radio-tracked animals during a drought in the 2002/2003 summer, and this was also captured by the model (Fig. 9, correlation analysis $r=0.79$, $P<0.001)$. However, the model moderately overestimated the decline in body condition due to reserves without the metabolic depression factor of 46\% (Fig. 9, see Methods).

The agreement between comparisons of observed and predicted masses and lengths of the 29 individuals from the long-term mark-recapture values varied strongly depending on whether water was assumed to be limiting (see Appendix S3 for all individual plots). For all 19 individuals that were near asymptotic length when first observed (Fig. 10a, b), the correlation coefficient was strongest for simulations assuming water limitation (average $r=0.37$, maximum of 0.59 ). All but 4 of these 19 correlations were statistically significant. However, only one case was statistically significant when lizards were simulated to have access to permanent water (average $r=0.0$, Appendix S3). In contrast, for all but 2 of the 10 individuals that were still growing in length at first capture (Fig. 10c, d), the correlation between observed and predicted mass was strongest for simulations assuming access to permanent water (average $r=0.6$ for non-limited vs. 0.38 for water-limited simulations).

\section{Continent-wide simulations under current and future climates}

Continent-wide simulations that assumed no water limitation (Fig. 11a) predicted high (>1,200 h/yr) potential activity over most of Australia, peaking at over $2000 \mathrm{~h} / \mathrm{yr}$ in the northeast of Australia. Lizards were only required to shelter deeper than $20 \mathrm{~cm}$ underground in the far north (to avoid heat) and the south-eastern highlands and the large southern island of Tasmania (to avoid cold), all of these areas being outside the species' range. No desiccation or starvation was predicted under this scenario and lizards were able to achieve maximum size within $20 \mathrm{yr}$ at all places except the aforementioned cold regions. Body mass exceeded $2 \mathrm{~kg}$ in the far north of Australia due to the accumulation of reproduction buffer, because the specified phenology of spring breeding did not permit multiple clutches. There was a strong latitudinal gradient in age of first reproduction, rising from six years in the far south of the range to two years in the far north of the range. Similarly, there was a latitudinal gradient in parturition month, shifting from autumn in the south to mid-summer in the north. Lifetime fecundity ranged from 10 to 35 across the current range. Outside the present geographic range, lifetime fecundity exceeded 40 in the very north, reducing to $<2$ in the extreme south. Survival probability mirrored the potential activity time as there was no other simulated influence on mortality rate.

When lizards were simulated to be water limited (Fig. 11b), i.e., acquiring water only from food or rainfall events $>3.5 \mathrm{~mm}$, activity time was severely restricted in the arid interior of the continent to the north and west of their present range. Throughout the continent, lizards were required to seek retreats $60 \mathrm{~cm}$ underground to avoid desiccation. Desiccation reached but rarely exceeded $20 \%$ throughout their current range and exceeded $35 \%$ in some inland areas. The activity restriction associated with moving underground to avoid desiccation resulted in substantial depletion of reserves, exceeding $70 \%$ in inland areas outside their present range but rarely exceeding $10 \%$ within their current range. Fecundity was generally reduced under the water-limited scenario but survival was higher due to the lower activity levels.

The use of age-specific fecundity and survival to compute the net reproductive rate $R_{0}$ (Fig. 12) produced values below one (i.e., negative population growth) only on the southern island of Tasmania, where the species is absent. When water was not assumed to be limiting (Fig. 12a), $R_{0}$ gradually increased from the southeast to the northwest. In contrast, under the water-limited scenario (Fig. 12b), $R_{0}$ dropped below one over large parts of inland Australia and maximal values occurred in the east of the continent.

Under the six climate change scenarios and with the assumption of water limitation, $R_{0}$ generally increased or remained constant across the species' current range (Fig. 13). Exceptions to this pattern were found for the ACCESS 1.3 and GDFLCM3 scenarios where $R_{0}$ declined slightly in central and western portions of the current geographic range. These declines only reduced $R_{0}$ to below one around the inland limit in the east-central part of the current range (Appendix S1: Fig. S3). In the inland and northern areas outside the current geographic range, $R_{0}$ varied substantially (Fig. 13). $R_{0}$ increased across the entire continent under all climate change scenarios when water was not assumed to be limiting (results not shown).

\section{Discussion}

The point of a mechanistic niche model is to infer environmental constraints on an organism through the explicit inclusion of potentially limiting processes. In the model we have presented, these processes included (1) the physical aspects driving the available microclimates to the study species above and below ground, including the influence of soil 


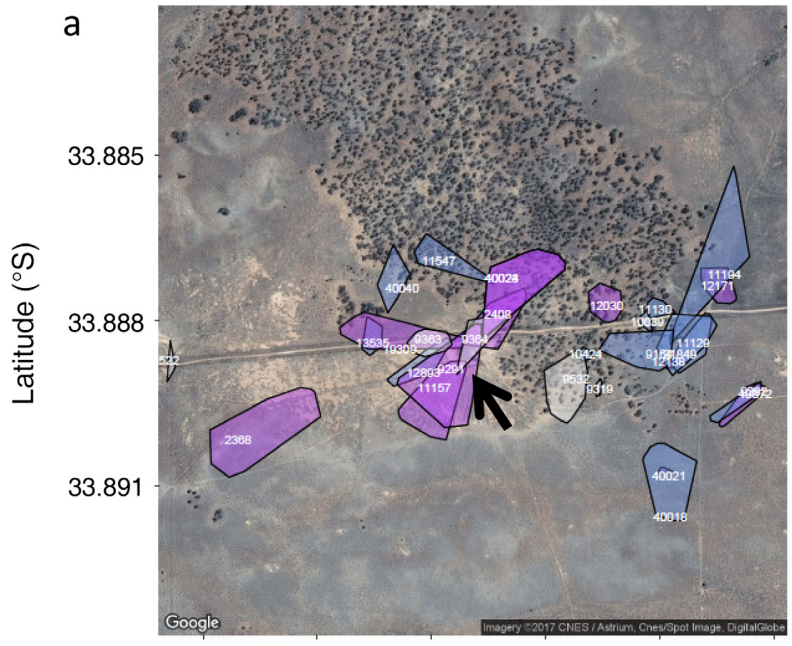

b
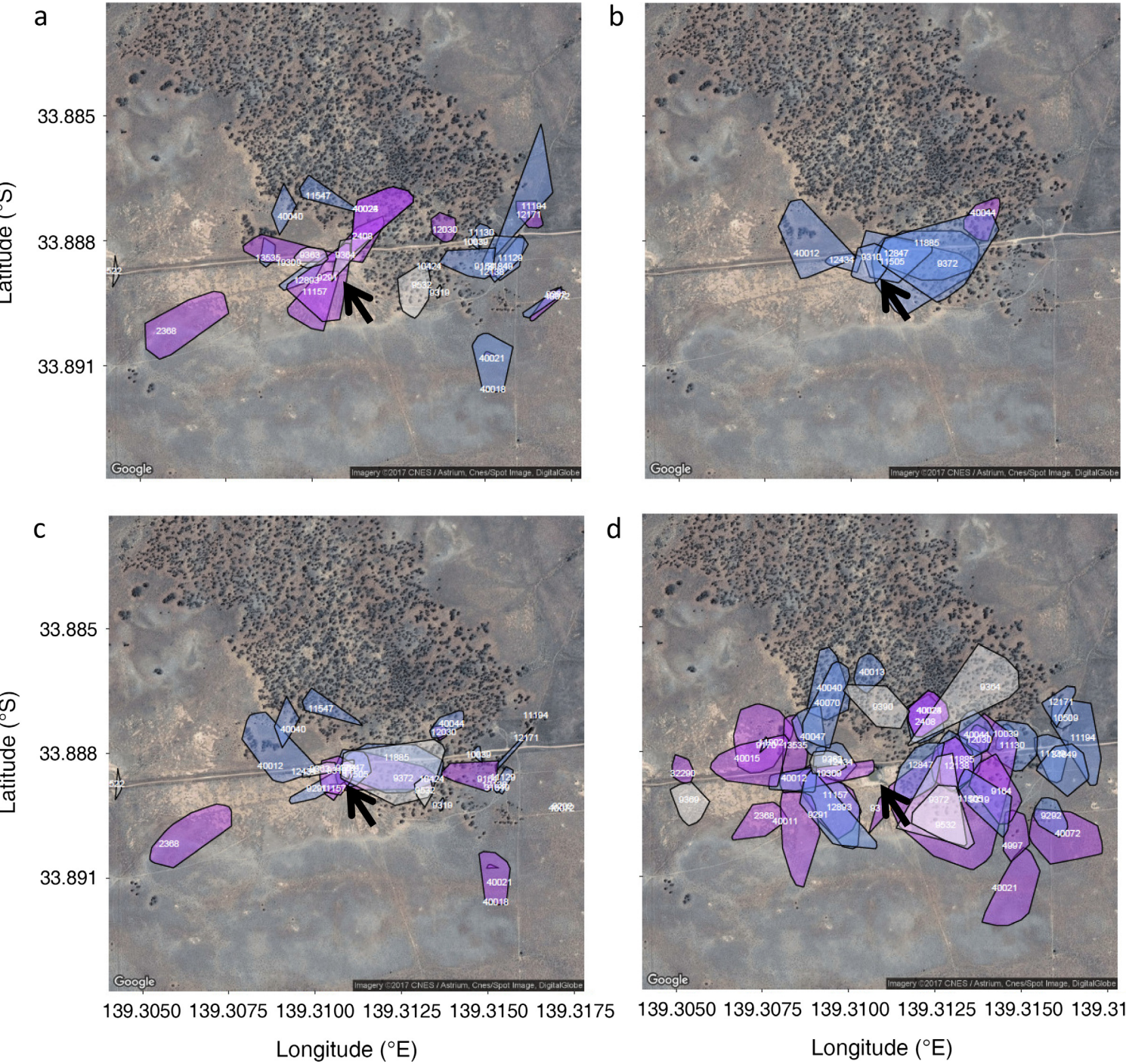

d

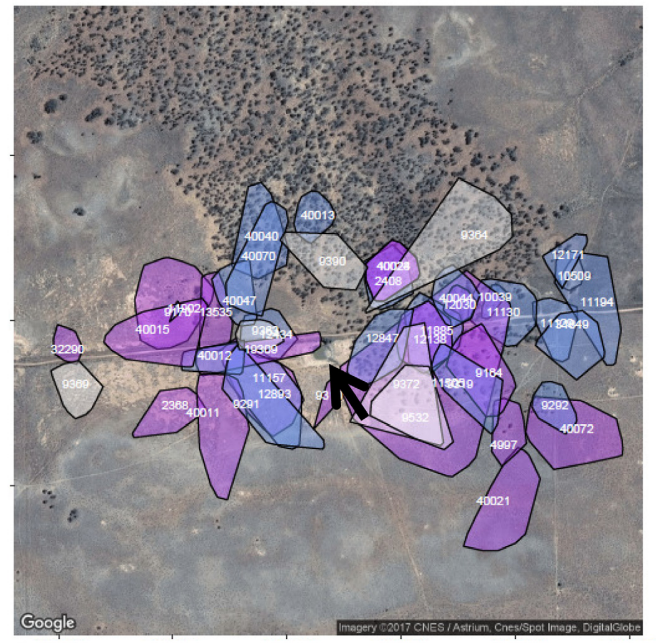

139.3050139 .3075139 .3100139 .3125139 .3150139 .3175

FIG. 8. Home ranges of (a) all the burrow-using lizards that were captured between 11 and 20 November, which was the end of a dry spell, (b) all lizards remaining active and not in burrows during the dry spell, (c) all lizards that were found in the week immediately before the dry-spell-breaking rainfall event of 21 November, irrespective of burrow use, and (d) all lizards that were found in the week immediately after the breaking of the dry spell. The black arrow shows the location of a farm dam, which held water during the study. Note how the lizards remaining active during the dry spell cluster around the water body (b) compared to those retreating to burrows in (a). Note also the clustering of individuals around the water just prior to the breaking of the dry spell (c) and the movement away from the water (and the increase in active individuals) after the rains come (d).

moisture on burrow humidity, (2) a model of food availability driven by soil moisture requirements for plant growth, (3) the processes of heat and water exchange and their effect on steady-state body temperature and evaporative water loss, (4) behavioral models of thermoregulation and hydroregulation, and (5) a complete dynamic energy and mass budget through the life cycle that predicts growth, development, and reproduction and that includes the interaction between feeding and the water budget. Because the model considers fundamental thermodynamic constraints and does not incorporate idiosyncratic biotic interactions or restricted habitat associations, the qualitative nature of the resultant predictions of climatic limitation will also hold for other functionally similar species (i.e., "dry-skinned" terrestrial ectotherms of moderate size and life span).
To have confidence in the internal coherence of such predictions and the generalities we can draw from them, however, it is important to ground-truth the various subprocesses of the model in the field. The modeling framework produces detailed hourly predictions at the scale of the individual organism, which can be compared directly with field observations. The detailed data available for our focal species provided a unique opportunity to test how well such a modeling system can predict body temperature, activity patterns, and growth in field-active ectotherms.

\section{How well did the mechanistic model work?}

Previous tests of biophysical predictions of field body temperature and activity patterns have been limited to 


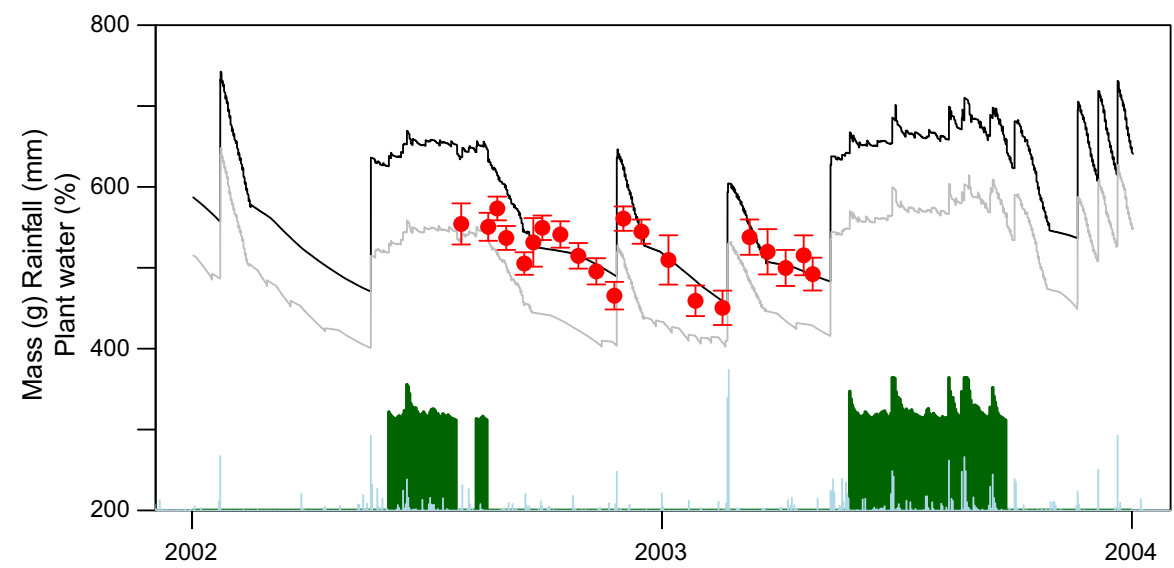

FIG. 9. Observed (red dots) body mass during the drought of the 2002/2003 summer (from Kerr and Bull, 2004) compared to that predicted with (black line) and without (gray line) a metabolic depression of $54 \%$ during estivation. Vertical blue lines represent rainfall events and vertical green lines represent simulated plant growth (each adjusted to the $y$-axis scale by multiplying by 6 and 2, respectively, and adding an offset of 200). Note the sudden jumps in observed and predicted wet mass after the two large rainfall events in the 2002/2003 summer.
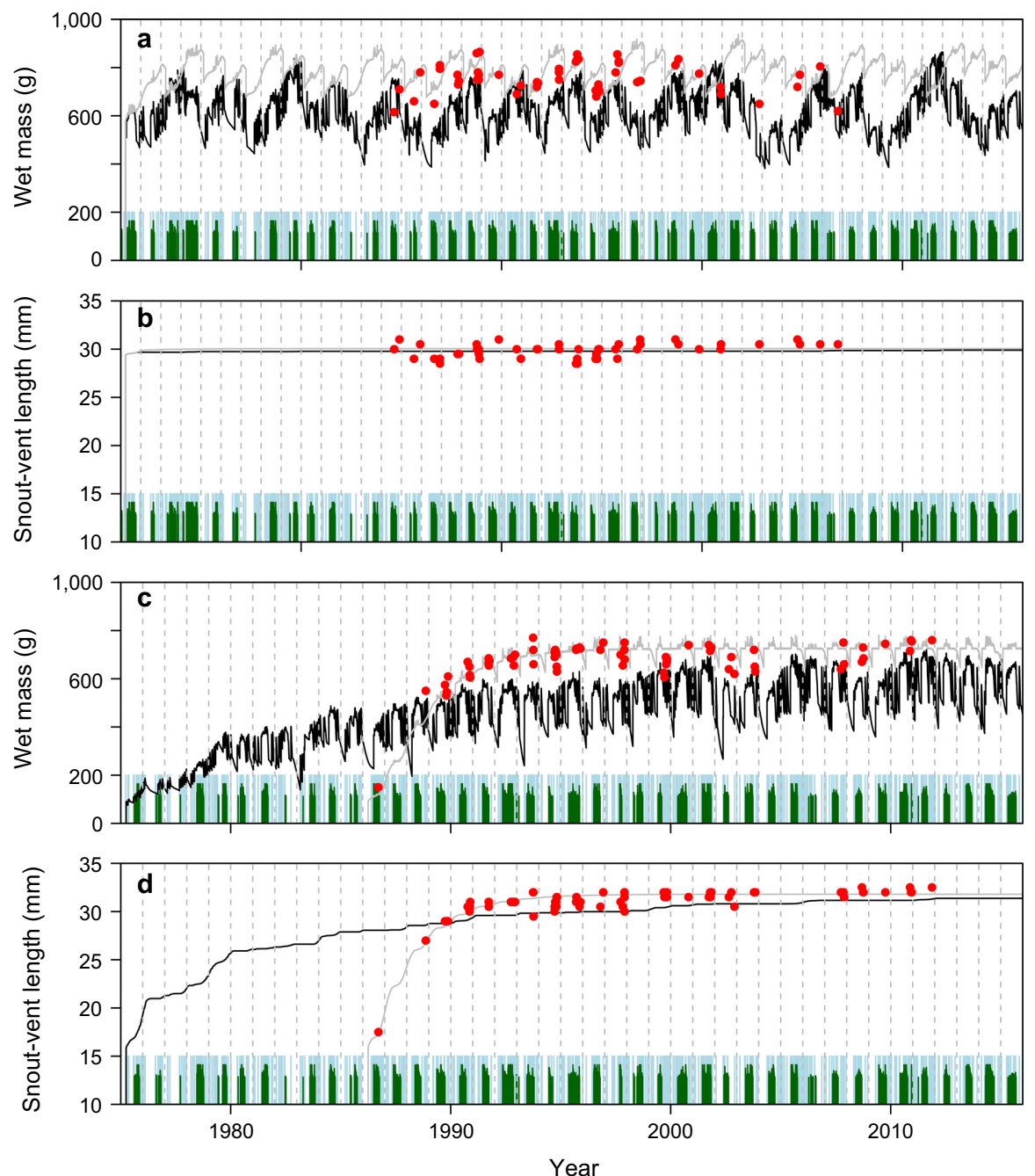

FIG. 10. Observed (red dots) mass and length with time for (a, b) a male (ID 2013) and (c, d) female (ID 3989) sleepy lizard compared to the simulated values assuming access to permanent water (gray line) or that water intake is limited by food and rainfall (black line). Green vertical lines at the base of each figure show when moist food was simulated to be available and the blue vertical lines show daily rainfall events $>3.5 \mathrm{~mm}$, which is the threshold permitting rehydration from drinking in the water-limited simulations. Vertical dotted gray lines denote the years. 
a Activity (h)
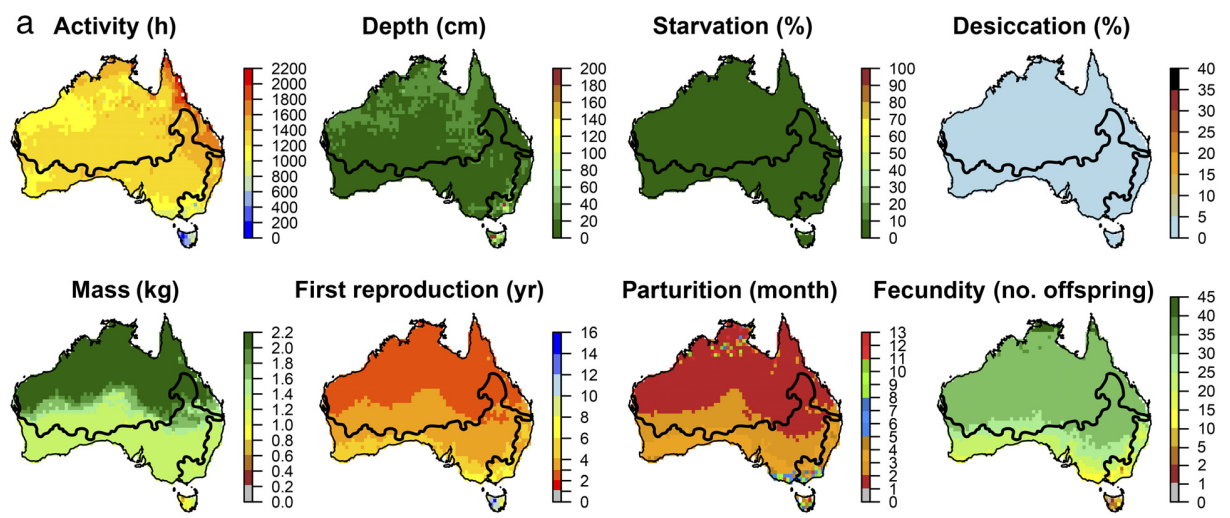

First reproduction (yr)
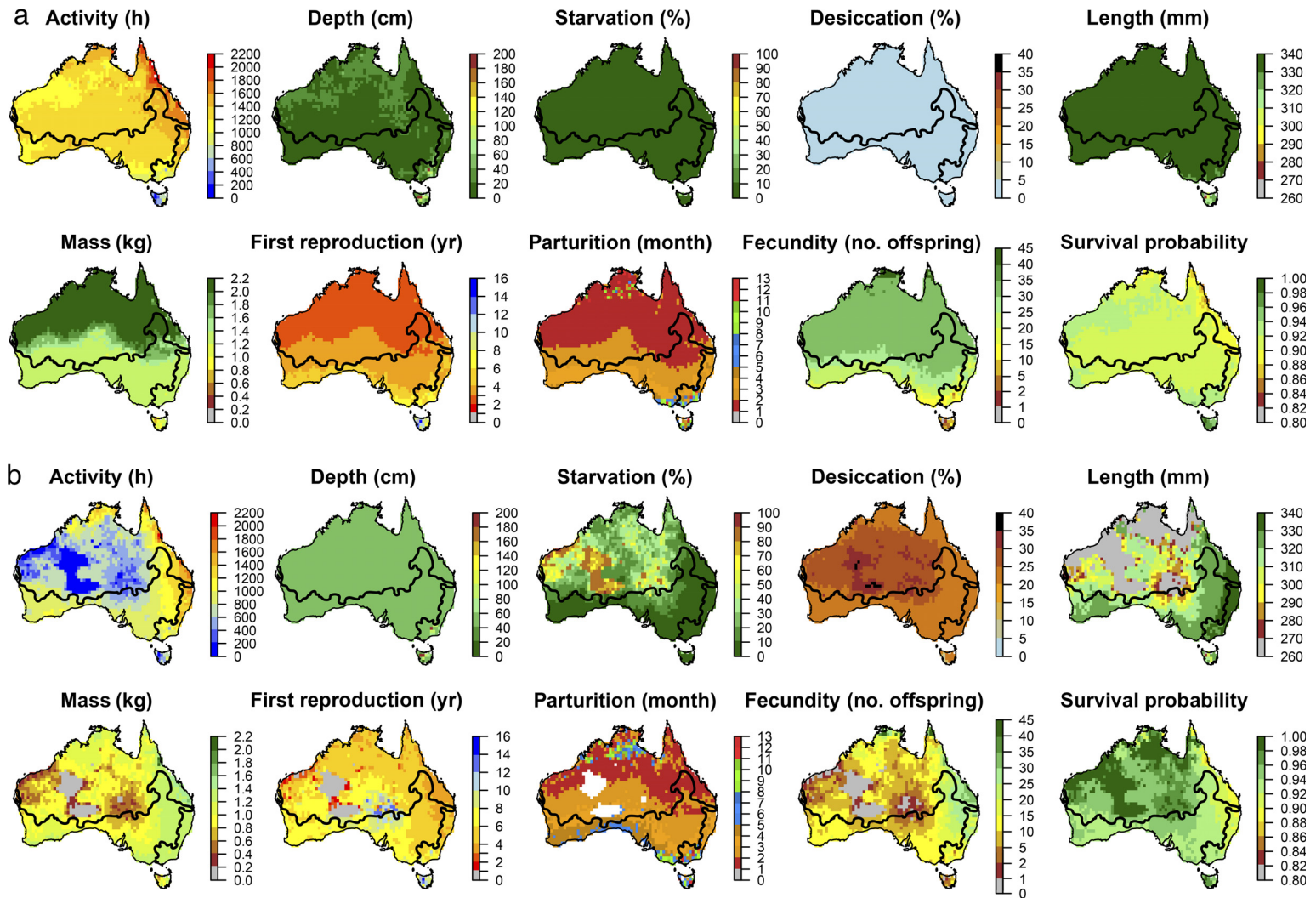

First reproduction (yr)

Parturition (month) Fecundity (no. offspring)
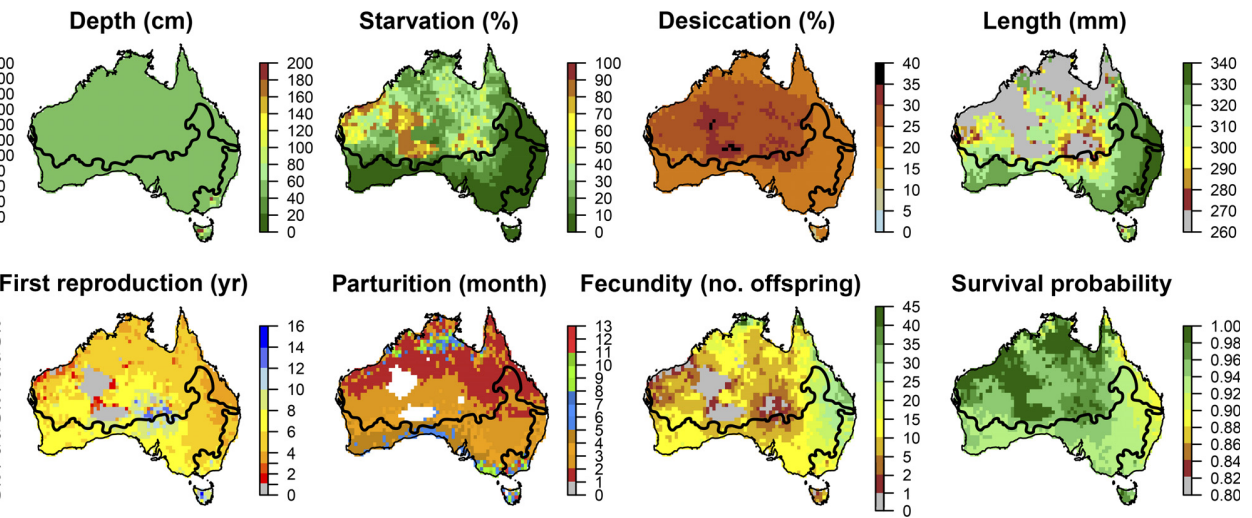

Survival probability

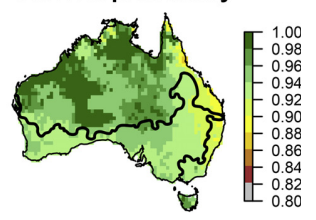

FIG. 11. Results of continent-wide simulations of potential activity time, maximum required depth, the maximum extent of starvation (reserve depletion) and desiccation, the maximum length and mass, the mean first year of reproduction, the mean parturition date, the mean fecundity, and survival. The simulations were run for $20 \mathrm{yr}$ (1990-2009) and repeated 20 times per site, starting as a hatchling in different years to capture cohort effects. The simulations either assumed (a) continuous access to water or (b) that water was only acquired via food and rainfall. The approximate boundary of the present distribution is indicated by the heavy black line, based on current records in the Atlas of Living Australia.
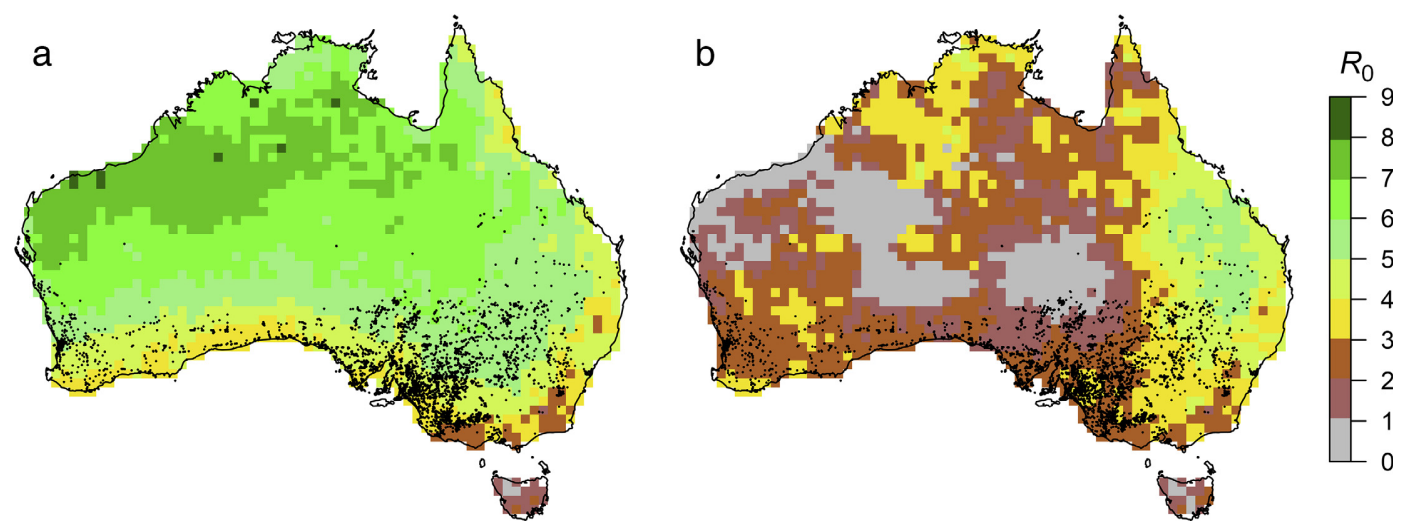

FIG. 12. Estimates of the net reproductive rate $R_{0}$ assuming water intake (a) was unlimited or (b) that it was limited by food and rainfall. The present distribution is indicated by the black dots.

short-term (days) behavioral observations of individuals while active (Porter et al. 1973, Porter and James 1979), with the recent exception of Sears et al. (2016). In the present study, we compared model predictions against 2-min observations of temperature and activity in over 60 lizards continuously made for over three months in each of two years. The modeling system was able to predict hourly mean body temperatures of these lizards to within $10 \%$, and could explain approximately $70 \%$ of daytime activity patterns. The unexplained variance in body temperature is likely to reflect (1) inaccuracies in the driving environmental data for predicting microclimates (the accuracy of lizard $T_{\mathrm{b}}$ prediction was of similar magnitude to that of near-surface soil temperature in Kearney et al. [2014], and microclimatic predictions presented in Appendix S1: Figs. S1, S2 for the Newhaven Sanctuary site); (2) variation among lizards in retreat site 

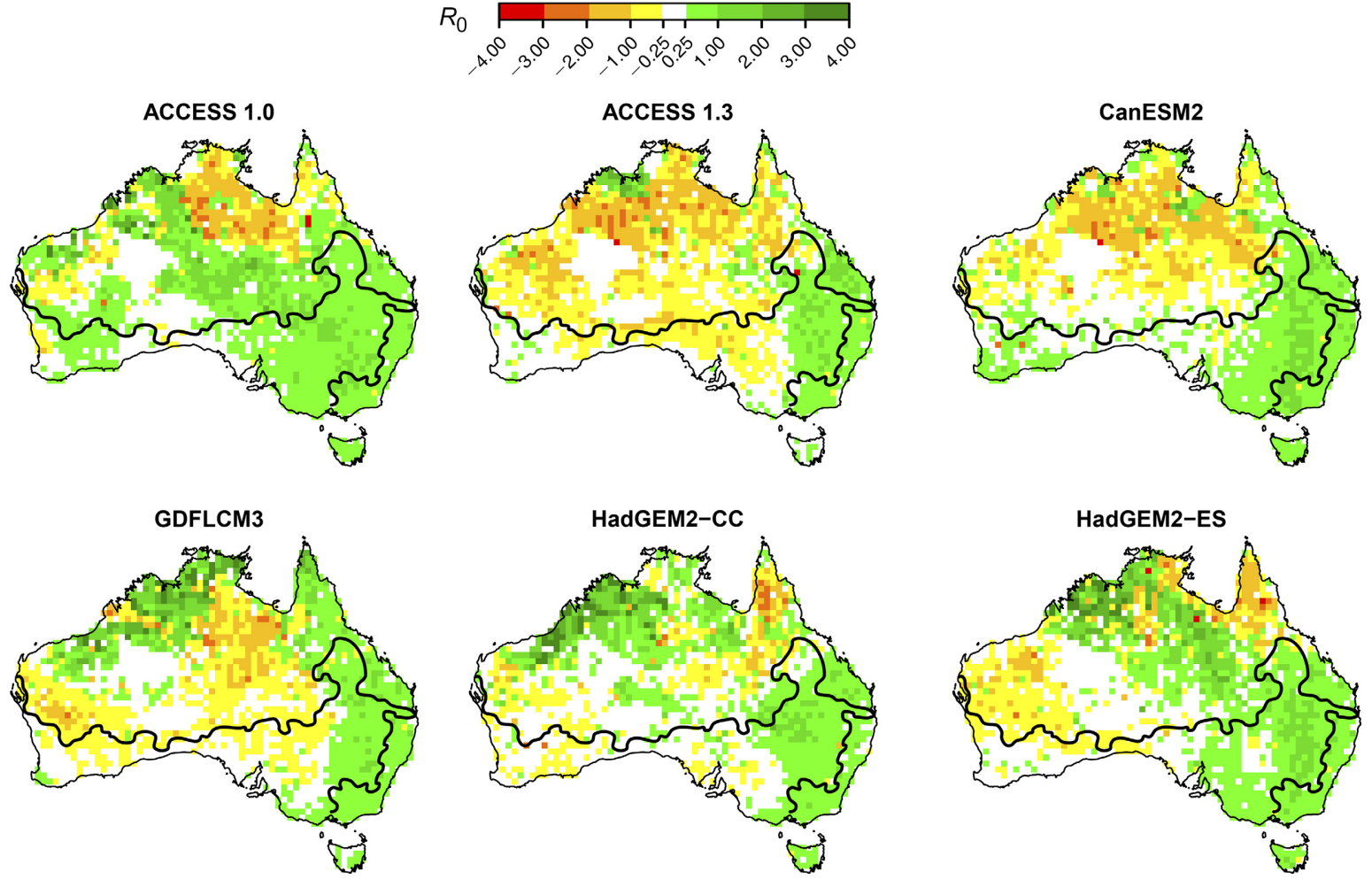

FIG. 13. Differences in net reproductive rate $\left(R_{0}\right)$ between six different climate change scenarios centered on 2070 and the mean of the base 1990-2009 simulations. The approximate boundary of the present distribution is indicated by the heavy black line.

selection and levels of activity; (3) the fact that we predicted core temperature but measured dorsal surface temperature (but see Chilton and Bull 1992, Berg et al. 2015); (4) our use of a steady-state heat budget model rather than a transient model (but see Malishev et al. 2017 for an application of a transient model to this species); and (5) variations in "personality" and motivational state among individual lizards (Godfrey et al. 2012, Spiegel et al. 2015).

While our model captured the overall thermal constraints on diurnal activity patterns (Fig. 5a), there was substantial variation in the extent that lizards exploited their available thermal windows for activity, some hardly moving during many periods of thermal suitability and others moving during most thermally available hours (Fig. 5b, c; Appendix S2). The lowest levels of activity were consistent with the DEBbased model predictions of required feeding rate, assuming lizards foraged whenever their stomachs were $<75 \%$ full, and could fill their stomach within an hour (Fig. 5c). Thus the system could predict the thermodynamic extremes of activity from the point of view of external (thermal environment) and the internal (metabolic) constraints. Higher levels of activity likely reflect courtship behavior, especially for males, which invest substantial time following their mate in addition to their own foraging (Kerr and Bull 2006b). Activity level may also reflect territory quality, with lower or more patchily distributed food densities necessitating more movement (Kerr and Bull 2006b). These issues likely contributed to the relatively high frequency $(21 \%)$ of records of lizards not moving in a daytime hour when the model predicted activity. The low incidence $(13 \%)$ of lizards moving during the day when the model predicted inactivity, however, is consistent with expectation of thermal conditions as a hard constraint on activity patterns.

The extensive mark-recapture data for the study species provided an unusual opportunity to assess how well the integrated biophysical model and DEB model could capture the dynamics of lizard mass and length. The body mass predicted by the model depends on the reserve density, the body water content, the stomach contents and the reproduction buffer level. When lizards were simulated to become inactive due to water limitation, they had already lost $20 \%$ of their body mass as water and then proceeded to lose additional mass due to both water and reserve depletion. We initially found that the body condition lost during the 2002-2003 drought was overestimated (Fig. 9). The observed sudden increases in mass after rainfall events in Fig. 9 are most likely due to a combination of rehydration from drinking and the consumption of moist vegetation (Kerr and Bull 2004). The magnitude of the simulated recovery in mass matched the observed values but the overall predicted background mass was lower due to excessive loss of reserves during desiccation-driven inactivity periods.

The success of the model in predicting field body temperature, activity, and growth trajectories is particularly encouraging given that the driving environmental input data we used were derived as interpolations from gridded products available at the continental scale, and many of the parameters considered were empirically defined rather than inversely fitted to the data (cf Higgins et al. 2012). 


\section{Water as a constraint on activity and growth}

Temperature broadly explained activity patterns and body temperatures of the lizards. However, at certain times water became the dominant driver. Most significantly, during a dry spell between 11 and 21 November in 2009 (Fig. 7; Appendix S2) the $T_{\mathrm{b}} \mathrm{s}$ of some individuals showed significantly reduced daily amplitude, matching expected temperatures at $\sim 60 \mathrm{~cm}$ underground (Fig. 6a; Appendix S2). The soil-moisture-based calculations predicted reduced plant water content in lizard food at this time. As a consequence, the mass budget calculations of the integrated biophysical/ DEB model predicted sustained water deficits in the lizards, consistent with declines in body mass observed during the dry spell (Fig. 6a; Appendix S2). Of the eight individuals that remained aboveground and active over this period, all but one had a home range intercepting the farm dam on the study site (Fig. 8b), with the single individual not overlapping the dam (male \# 40044) also being the only one of these eight individuals to lose condition over the dry spell (Appendix S2). The causal role of water is strongly supported by the fact that body temperature cycles, activity, recapture success, and body condition all sharply returned to normal values following a large rainfall event on 21 November, and by the reduced clustering of home ranges around the farm dam in the week after compared to the week preceding this rainfall event (Fig. 8c, d; see also Leu and Bull 2016).

During the dry spell, our data indicate that lizards retreated to deep refuges. Humidity in the air spaces of dry desert soil can be near saturated (Schmidt-Nielsen and Schmidt-Nielsen 1950, Campbell and Norman 1998). Burrows, while more coupled to atmospheric humidity, can also have very high humidity (Schmidt-Nielsen and Schmidt-Nielsen 1950). We did not measure humidity in the lizard burrows at the study site (but see Warburg 1965, Shimmin et al. 2002). However, we observed near-saturation humidity below $50 \mathrm{~cm}$ in burrows of the great desert skink Liopholis kintorei in a more arid site and were able to simulate this successfully with a logarithmically weighted mean of predicted near-surface and soil pore-space humidity (Fig. 2). For desert rodents and lizards, high burrow humidity allows metabolic water production to balance the reduced rates of evaporative water loss (Schmidt-Nielsen and Schmidt-Nielsen 1950, Nagy 1972). This is consistent with our modeled water balance of lizards sheltering underground (Fig. 5a). The sleepy lizard has relatively water-resistant skin for a reptile (Warburg 1965) and its relatively large size, and therefore low surface area to volume ratio, should also buffer it against water loss. Thus, our findings imply that water could often be limiting activity in dry-skinned terrestrial ectotherms from temperate, seasonally dry and arid areas, and that humid retreats may become important resources at these times.

Water could also be seen as a powerful influence on our predictions of body condition and growth. For example correlations between observed and predicted mass were stronger when they included dry periods. A weak correlation between observed and predicted body mass might be expected in part because of the substantial additional fluctuations in mass of females due to reproduction in females as they build up their reproduction buffers (approximately 25\% of their body mass) and give birth. Thus predictions for females are likely to be out of phase with respect to this reproductive dynamic (females do not reproduce every year) but not with respect to dehydration. Accordingly, for the mass observations of the wild individuals from the activity study, correlations with simulated body mass were far stronger in 2009 when the dry spell occurred than in 2010 when there was no evidence of desiccation-induced inactivity (Appendix S2). Moreover, for the longer-term mark-recapture data (Fig. 10; Appendix S3) the correlations of predicted and observed body mass were stronger for waterlimited simulations than for non-limited simulations. This was especially so for individuals that were already adult from the beginning of the mark-recapture time series. For individuals captured as juveniles during the mark-recapture study, simulations assuming access to water provided a far better correlation with observed growth trajectories than those assuming water-limited growth (Fig. 10; Appendix S3). As already mentioned, individuals with home ranges close to permanent water sources may have a substantial advantage in terms of growth and body condition (Leu and Bull 2016) and our simulations suggest that the juveniles in the mark-recapture data set had access to water as they grew.

\section{The relative roles of water and temperature in constraining distribution}

At the distribution scale, temperature was not found to be a constraint on the northern or inland limit of the sleepy lizard (Fig. 11a). We allowed the simulated individuals to take shelter in retreats as deep as $1 \mathrm{~m}$ but retreats no deeper than $40 \mathrm{~cm}$ were required to avoid daily high-temperature extremes throughout most of the continent (Fig. 11a, see also Appendix S1: Fig. S2). However, water acted as a potent constraint on the inland distribution limit, with substantial activity restriction leading to depressed growth and reproduction (Fig. 11b). Moreover, beyond the interior margin of the species' distribution limit, individuals taking refuge $60 \mathrm{~cm}$ underground in humid burrows lost more than $20 \%$ of their body mass as water, exceeding $35 \%$ in some areas (Fig. 11b). The net balance of age-specific fecundity and activity-related mortality produced net reproductive rates $<1$ in the central and northwest parts of inland Australia (Fig. 12b) suggesting desiccation stress is a limiting factor. These findings are consistent with a recent demographic analysis of a $30 \mathrm{yr}$ mark-recapture study in the vicinity of our field study site, where below-average survival was correlated with hot, dry winter/spring conditions (Jones et al. 2016).

What do our findings imply about the direct thermodynamic effects of climate change? Water stress is increasingly appreciated as a key stress for endotherms under climate change (Albright et al. 2017). Mechanistic studies of the physiological impact of climate and climate change on dryskinned ectotherms have been highly focused on temperature and associated traits, with key themes being survival during temperature extremes (Sunday et al. 2014) and thermally imposed activity restriction (Sinervo et al. 2010). In contrast, our simulations indicate that the direct influence of future climate change on the focal species is likely to be 
neutral or beneficial (Fig. 13; Appendix S1: Fig. S3), a result driven largely by an increase in the rates of growth and reproduction.

The response of the sleepy lizard and functionally similar species to climate change will, however, depend intimately on future patterns of rainfall, a highly uncertain aspect of general circulation models. Our predictions included the synergistic effects of changed air temperature and precipitation regimes on food availability (via soil moisture), shelter humidity and evaporative water loss. The interaction between these processes is non-linear and hard to intuit. For example, juvenile individuals are inherently more vulnerable to desiccation due to their higher surface area to volume ratios and reduced ability to tolerate prolonged periods of drought. Climate warming may therefore impose greater desiccation stress due to stronger vapor pressure gradients, irrespective of changes in rainfall. But the faster growth rates imposed by warmer conditions could allow more rapid transitions out of the desiccation-sensitive juvenile stages. Moreover, the nature of these interactions will vary strongly with a species' body size and diet.

There is a wide range of specialized adaptations to water stress across animal taxa, including the water-tight cocoons of frogs (Cartledge et al. 2006), turbinates of mammals (Schmidt-Nielsen 1964), and discontinuous gas exchange in insects (White et al. 2007). Such adaptations can be captured in the parameter values of the general modeling framework presented here through changes in the relevant model parameters (i.e., the skin resistance to water loss, the temperature differential of expired air, and the oxygen extraction efficiency, respectively, for the above examples) and assessed in the context of metabolic and microclimatic constraints. The limits of such adaptations can then be considered in environmentally realistic scenarios across whole life cycles.

\section{Conclusion}

Mechanistic niche models are increasing in the ecological literature but field validations of their predictions are extremely rare. In our detailed analysis for the sleepy lizard, we have found that predictions of hourly scale microclimates, activity and body temperature, and years to decadal-scale body condition and growth, are feasible, realistic and coherent. The detailed contrasts between models and data also revealed important individual-scale variation, most notably the range of activity levels (which fell between our extremes of thermally based and metabolically based constraints) and the potential influence of water limitation. As pointed out by Urban et al. (2016), detailed applications of mechanistic models can be of value in pointing to novel processes, and failures of such models are just as useful as successes because they pinpoint areas where our understanding is lacking. For these reasons, future mechanistic niche modeling exercises need to be developed in close connection with field data wherever possible. The modeling framework we have applied in this study is highly general and captures fundamental processes relevant to any terrestrial ectotherm, that is, heat exchange, water exchange, thermoregulatory behavior, energy uptake, and allocation (including growth and reproduction). Our findings with respect to the sleepy lizard therefore highlight the general importance of understanding hydrological constraints in addition to, and in interaction with, thermal constraints when considering the effects of climate and climate change on terrestrial ectotherms.

\section{ACKNOWLEDGMENTS}

This work was supported by ARC Discovery grants DP140101240 and DP110102813 to M. R. Kearney and DP0877384 to C. M. Bull. It was also supported by a resource allocation grant from the Victorian Life Sciences Computation Initiative (Melbourne Bioinformatics) to M. R. Kearney and an Australia and Pacific Science Foundation grant APSF $13 / 5$ to M. R. Kearney and D. Moore. The work was conducted under Flinders Animal Welfare Permit E232, South Australian Department of Environment Water and Natural Resources Research Permit A23436, James Cook University Animal Ethics permits A1159, A1478, A1864, and Queensland EPA permits WISP 06328209, WISP12106012. We dedicate this work to the memories of Mike Bull and his long-term field technician Dale Burzacott, who both passed away before the work was completed.

\section{Literature Cited}

Adolph, S. C., and W. P. Porter. 1993. Temperature, activity and lizard life histories. American Naturalist 142:273-295.

Albright, T. P., D. Mutiibwa, A. R. Gerson, E. K. Smith, W. A. Talbot, J. J. O'Neill, A. E. McKechnie, and B. O. Wolf. 2017. Mapping evaporative water loss in desert passerines reveals an expanding threat of lethal dehydration. Proceedings of the National Academy of Sciences USA 114:2283-2288.

Andrewartha, H. G., and L. C. Birch. 1954. The distribution and abundance of animals. The University of Chicago Press, Chicago, Illinois, USA.

Angilletta, M. J. 2009. Thermal adaptation: A theoretical and empirical synthesis. Oxford University Press, Oxford, UK.

Barwick, R. E. 1965. Studies on the scincid lizard Egernia cunninghami (Gray, 1832). Dissertation. Australian National University, Canberra, Australian Capital Territory, Australia.

Bennett, A. F. 1973. Ventilation in two species of lizards during rest and activity. Comparative Biochemistry and Physiology Part A: Physiology 46:653-671.

Bennett, A. F., and H. John-Alder. 1986. Thermal relations of some Australian skinks (Sauria: Scincidae). Copeia 1986:57-64.

Bentley, P. J. 1959a. Effects of elevated plasma sodium concentration on sodium and potassium in the erythrocyte of the lizard Trachysaurus rugosus (Gray). Nature 184:1403.

Bentley, P. J. 1959b. Studies on the water and electrolyte metabolism of the lizard Trachysaurus rugosus (Gray). Journal of Physiology 145:37-47.

Bentley, P. J., and K. Schmidt-Nielsen. 1966. Cutaneous water loss in reptiles. Science 151:1547-1549.

Berg, W., O. Theisinger, and K. H. Dausmann. 2015. Evaluation of skin temperature measurements as suitable surrogates of body temperature in lizards under field conditions. Herpetologica 46:157-161.

Bradshaw, S. D. 1970. Seasonal changes in the water and electrolyte metabolism of Amphibolurus lizards in the field. Comparative Biochemistry and Physiology 36:689-717.

Bradshaw, S. D. 1977. The regulation of water and electrolyte balance in desert lizards. Pages 161-178 in H. Messel and S. T. Butler, editors. Australian animals and their environment. Shakespeare Head Press, Sydney, New South Wales, Australia.

Bradshaw, S. D. 1986. Ecophysiology of desert reptiles. Academic Press Australia, North Ryde, New South Wales, Australia.

Brand-Miller, J., and S. Holt. 1998. Australian Aboriginal plant foods: a consideration of their nutritional composition and health implications. Nutrition Research Reviews 11:5-23.

Briscoe, N. J., M. R. Kearney, C. A. Taylor, and B. A. Wintle. 2016. Unpacking the mechanisms captured by a correlative species distribution model to improve predictions of climate refugia. Global Change Biology 22:2425-2439. 
Buckley, L. B. 2008. Linking traits to energetics and population dynamics to predict lizard ranges in changing environments. American Naturalist 171:E1-E19.

Buckley, L. B. 2010. The range implications of lizard traits in changing environments. Global Ecology and Biogeography 19:452-464.

Bull, C. M. 1987. A population study of the viviparous Australian lizard, Trachydosaurus rugosus (Scincidae). Copeia 1987:749-757.

Bull, C. M. 1995. Population ecology of the sleepy lizard, Tiliqua rugosa, at Mt Mary, South Australia. Australian Journal of Ecology 20:393-402.

Bull, C. M., S. J. B. Cooper, and B. C. Baghurst. 1998. Social monogamy and extra-pair fertilization in an Australian lizard, Tiliqua rugosa. Behavioral Ecology and Sociobiology 44:63-72.

Bull, C. M., S. S. Godfrey, and D. M. Gordon. 2012. Social networks and the spread of Salmonella in a sleepy lizard population. Molecular Ecology 21:4386-4392.

Bull, C. M., A. McNally, and G. Dubas. 1991. Asynchronous seasonal activity of male and female sleepy lizards, Tiliqua rugosa. Journal of Herpetology 25:436-441.

Bull, C. M., Y. Pamula, and L. Schulze. 1993. Parturition in the sleepy lizard, Tiliqua rugosa. Journal of Herpetology 27:489-492.

Campbell, G. S. 1985. Soil physics with basic: transport models for soil-plant systems. Elsevier, Amsterdam, The Netherlands.

Campbell, G. S., and J. M. Norman. 1998. Environmental biophysics. Springer, New York, New York, USA.

Cartledge, V. A., P. C. Withers, K. A. McMaster, G. G. Thompson, and S. D. Bradshaw. 2006. Water balance of field-excavated aestivating Australian desert frogs, the cocoon-forming Neobatrachus aquilonius and the non-cocooning Notaden nichollsi (Amphibia: Myobatrachidae). Journal of Experimental Biology 209:3309-3321.

Ceia-Hasse, A., B. Sinervo, L. Vicente, and H. M. Pereira. 2014. Integrating ecophysiological models into species distribution projections of European reptile range shifts in response to climate change. Ecography 37:679-688.

Chilton, N. B., and C. M. Bull. 1992. The on-host temperature environment for two Australian reptile ticks. Australian Journal of Zoology 40:583-592.

Chown, S. L., C. J. Klok, and M. A. McGeoch. 2004. Weather to go out: activity of Bothrometopus brevis (Curculionidae) at Heard Island. Polar Biology 27:217-221.

Chown, S. L., J. G. Sorensen, and J. S. Terblanche. 2011. Water loss in insects: an environmental change perspective. Journal of Insect Physiology 57:1070-1084.

Christian, K. A., G. S. Bedford, and S. T. Shannahan. 1996. Solar absorptance of some Australian lizards and its relationship to temperature. Australian Journal of Zoology 44:59-67.

Christian, K. A., G. S. Bedford, and T. J. Schultz. 1999. Energetic consequences of metabolic depression in tropical and temperatezone lizards. Australian Journal of Zoology 47:133-141.

Crozier, L., and G. Dwyer. 2006. Combining population-dynamic and ecophysiological models to predict climate-induced insect range shifts. American Naturalist 167:853-866.

Dai, A. 2013. Increasing drought under global warming in observations and models. Nature Climate Change 3:52-58.

Davis, J. R., and D. F. DeNardo. 2010. Seasonal patterns of body condition, hydration state, and activity of gila monsters (Heloderma suspectum) at a Sonoran Desert site. Journal of Herpetology 44:83-93.

Davis, A. J., L. S. Jenkinson, J. H. Lawton, B. Shorrocks, and S Wood. 1998. Making mistakes when predicting shifts in species range in response to global warming. Nature 391:783-786.

Deutsch, C. A., J. J. Tewksbury, R. B. Huey, K. S. Sheldon, C. K. Ghalambor, D. C. Haak, and P. R. Martin. 2008. Impacts of climate warming on terrestrial ectotherms across latitude. Proceedings of the National Academy of Sciences USA 105:6668-6672.

Dillon, M. E., G. Wang, and R. B. Huey. 2010. Global metabolic impacts of recent climate warming. Nature 467:704-706.

Dormann, C. F., et al. 2012. Correlation and process in species distribution models: bridging a dichotomy. Journal of Biogeography 39:2119-2131.
Dubas, G., and C. M. Bull. 1991. Diet choice and food availability in the omnivorous lizard, Trachydosaurus rugosus. Wildlife Research 18:147-155.

Dunham, A. E. 1993. Population responses to environmental change: operative environments, physiologically structured models, and population dynamics. Pages $95-119$ in P. M. Kareiva, J. G. Kingsolver, and R. B. Huey, editors. Biotic interactions and global change. Sinauer Associates, Sunderland, Massachusetts, USA.

Dunham, A. E., B. W. Grant, and K. L. Overall. 1989. Interfaces between biophysical and physiological ecology and the population ecology of terrestrial vertebrate ectotherms. Physiological Zoology 62:335-355.

Ehrlén, J., and W. F. Morris. 2015. Predicting changes in the distribution and abundance of species under environmental change. Ecology Letters 18:303-314.

Eynan, M., and R. Dmi'el. 1993. Skin resistance to water Loss in agamid lizards. Oecologia 95:290-294.

Godfrey, S. S., T. H. Ansari, M. G. Gardner, D. R. Farine, and C. M. Bull. 2014. A contact-based social network of lizards is defined by low genetic relatedness among strongly connected individuals. Animal Behaviour 97:35-43.

Godfrey, S. S., J. K. Bradley, A. Sih, and C. M. Bull. 2012. Lovers and fighters in sleepy lizard land: Where do aggressive males fit in a social network? Animal Behaviour 83:209-215.

Hertz, P. E., R. B. Huey, and R. D. Stevenson. 1993. Evaluating temperature regulation by field-active ectotherms: the fallacy of the inappropriate question. American Naturalist 142:796-818.

Higgins, S. I., et al. 2012. A physiological analogy of the niche for projecting the potential distribution of plants. Journal of Biogeography 39:2132-2145.

Huey, R. B. 1982. Temperature, physiology, and the ecology of reptiles. Pages 25-91 in C. Gans and F. H. Pough, editors. Physiology C: physiological ecology. Academic Press, London, UK.

Huey, R. B., C. A. Deutsch, J. J. Tewksbury, L. J. Vitt, P. E. Hertz, H. J. Álvarez Pérez, and T. Garland. 2009. Why tropical forest lizards are vulnerable to climate warming. Proceedings of the Royal Society B 276:1939-1948.

Huey, R. B., M. R. Kearney, A. Krockenberger, J. A. M. Holtum, M. Jess, and S. E. Williams. 2012. Predicting organismal vulnerability to climate warming: roles of behaviour, physiology and adaptation. Philosophical Transactions of the Royal Society B 367:1665-1679.

Huey, R. B., J. B. Losos, and C. Moritz. 2010. Are lizards toast? Science 328:832-833.

Hughes, L. 2000. Biological consequences of global warming: is the signal already apparent? Trends in Ecology \& Evolution 15:56-61.

Jones, A. R., C. M. Bull, B. W. Brook, K. Wells, K. H. Pollock, and D. A. Fordham. 2016. Tick exposure and extreme climate events impact survival and threaten the persistence of a long-lived lizard. Journal of Animal Ecology 85:598-610.

Kearney, M. 2012. Metabolic theory, life history and the distribution of a terrestrial ectotherm. Functional Ecology 26:167-179.

Kearney, M. R. 2013. Activity restriction and the mechanistic basis for extinctions under climate warming. Ecology Letters 16:14701479 .

Kearney, M. R., and J. L. Maino. 2018. Can next-generation soil data products improve soil moisture modelling at the continental scale? An assessment using a new microclimate package for the R programming environment. Journal of Hydrology 561:662-673.

Kearney, M., B. L. Phillips, C. R. Tracy, K. Christian, G. Betts, and W. P. Porter. 2008. Modelling species distributions without using species distributions: the cane toad in Australia under current and future climates. Ecography 31:423-434.

Kearney, M., and W. P. Porter. 2004. Mapping the fundamental niche: physiology, climate, and the distribution of a nocturnal lizard. Ecology 85:3119-3131.

Kearney, M. R., and W. P. Porter. 2017. NicheMapR—an R package for biophysical modelling: the microclimate model. Ecography 40:664-674. 
Kearney, M., W. P. Porter, C. K. Williams, S. A. Ritchie, and A. A. Hoffmann. 2009a. Integrating biophysical models and evolutionary theory to predict climatic impacts on species' ranges: the dengue mosquito Aedes aegypti in Australia. Functional Ecology 23:528-538.

Kearney, M. R., A. Shamakhy, R. Tingley, D. J. Karoly, A. A. Hoffmann, P. R. Briggs, and W. P. Porter. 2014. Microclimate modelling at macro scales: a test of a general microclimate model integrated with gridded continental-scale soil and weather data. Methods in Ecology and Evolution 5:273-286.

Kearney, M., R. Shine, and W. P. Porter. 2009b. The potential for behavioral thermoregulation to buffer "cold-blooded" animals against climate warming. Proceedings of the National Academy of Sciences USA 106:3835-3840.

Kearney, M. R., S. J. Simpson, D. Raubenheimer, and S. A. L. M. Kooijman. 2013. Balancing heat, water and nutrients under environmental change: a thermodynamic niche framework. Functional Ecology 27:950-966

Kerr, G. D., and C. M. Bull. 2004. Field observations of extended locomotor activity at sub-optimal body temperatures in a diurnal heliothermic lizard (Tiliqua rugosa). Journal of Zoology 264:179188 .

Kerr, G. D., and C. M. Bull. 2006a. Exclusive core areas in overlapping ranges of the sleepy lizard, Tiliqua rugosa. Behavioral Ecology 17:380-391.

Kerr, G. D., and C. M. Bull. 2006b. Movement patterns in the monogamous sleepy lizard (Tiliqua rugosa): effects of gender, drought, time of year and time of day. Journal of Zoology 269:137-147.

Kerr, G. D., M. J. Bottema, and C. M. Bull. 2008. Lizards with rhythm? Multi-day patterns in total daily movement. Journal of Zoology 275:79-88.

Kerr, G. D., C. M. Bull, and D. Burzacott. 2003. Refuge sites used by the scincid lizard Tiliqua rugosa. Austral Ecology 28:152-160.

Kerr, G. D., C. M. Bull, and G. R. Cottrell. 2004. Use of an "on board" datalogger to determine lizard activity patterns, body temperature and microhabitat use for extended periods in the field Wildlife Research 31:171-176.

Kooijman, S. A. L. M. 2010. Dynamic energy budget theory for metabolic organisation. Cambridge University Press, Cambridge, UK.

Leu, S. T., and C. M. Bull. 2016. Artificial water point for livestock influences spatial ecology of a native lizard species. PLoS ONE 11:e0147433.

Levy, O., J. D. Borchert, T. W. Rusch, L. B. Buckley, and M. J. Angilletta. 2017. Diminishing returns limit energetic costs of climate change. Ecology 98:1217-1228.

Levy, O., L. B. Buckley, T. H. Keitt, and M. J. Angilletta. 2016 Ontogeny constrains phenology: opportunities for activity and reproduction interact to dictate potential phenologies in a changing climate. Ecology Letters 19:620-628.

Lika, K., M. R. Kearney, V. Freitas, H. W. van der Veer, J. van der Meer, J. W. M. Wijsman, L. Pecquerie, and S. A. L. M. Kooijman. 2011a. The "covariation method" for estimating the parameters of the standard dynamic energy budget model I: philosophy and approach. Journal of Sea Research 66:270-277.

Lika, K., M. R. Kearney, and S. A. L. M. Kooijman. 2011b. The "covariation method" for estimating the parameters of the standard dynamic energy budget model II: properties and preliminary patterns. Journal of Sea Research 66:278-288.

Llandres, A. L., G. M. Marques, J. L. Maino, S. A. L. M. Kooijman, M. R. Kearney, and J. Casas. 2015. A dynamic energy budget for the whole life-cycle of holometabolous insects. Ecological Monographs 85:353-371.

Lorenzon, P., J. Clobert, A. Oppliger, and H. John-Alder. 1999. Effect of water constraint on growth rate, activity and body temperature of yearling common lizard (Lacerta vivipara). Oecologia 118:423-430.

Maino, J. L., J. D. Kong, A. A. Hoffmann, M. G. Barton, and M. R. Kearney. 2016. Mechanistic models for predicting insect responses to climate change. Current Opinion in Insect Science 17:81-86.

Malishev, M., C. M. Bull, and M. R. Kearney. 2017. An individualbased model of ectotherm movement integrating metabolic and microclimatic constraints. Methods in Ecology and Evolution 9:472-489.

Marques, G. M., S. Augustine, K. Lika, L. Pecquerie, T. Domingos, and S. A. L. M. Kooijman. 2018. The AmP project: comparing species on the basis of dynamic energy budget parameters. PLOS Computational Biology 14:e1006100.

McVicar, T. R., T. G. Van Niel, L. T. Li, M. L. Roderick, D. P. Rayner, L. Ricciardulli, and R. J. Donohue. 2008. Wind speed climatology and trends for Australia, 1975-2006: capturing the stilling phenomenon and comparison with near-surface reanalysis output. Geophysical Research Letters 35:L20403.

Medina, M., A. Scolaro, F. Méndez-De la Cruz, B. Sinervo, D. B. Miles, and N. Ibargüengoytía. 2012. Thermal biology of genus Liolaemus: a phylogenetic approach reveals advantages of the genus to survive climate change. Journal of Thermal Biology 37:579-586.

Moore, D., A. Stow, and M. R. Kearney. 2018. Under the weather? - the direct effects of climate warming on a threatened desert lizard are mediated by their activity phase and burrow system. Journal of Animal Ecology 87:660-671.

Mouquet, N., et al. 2015. REVIEW: predictive ecology in a changing world. Journal of Applied Ecology 52:1293-1310.

Nagy, K. A. 1972. Water and electrolyte budgets of a free-living desert lizard, Sauromalus obesus. Journal of Comparative Physiology A: Neuroethology, Sensory, Neural, and Behavioral Physiology 79:39-62.

Packard, G. C., and M. J. Packard. 1988. Water relations of embryonic snapping turtles (Chelydra serpentina) exposed to wet or dry environments at different times in incubation. Physiological Zoology 61:95-106.

Pamula, Y. 1997. Reproduction in the viviparous skink Tiliqua rugosa. Flinders University, Adelaide, South Australia, Australia.

Parmesan, C. 2006. Ecological and evolutionary responses to recent climate change. Annual Review of Ecology and Systematics 37:637-669.

Petchey, O. L., et al. 2015. The ecological forecast horizon, and examples of its uses and determinants. Ecology Letters 18:597611.

Pirtle, E. I., C. R. Tracy, and M. R. Kearney. in press. Hydroregulation - a neglected behavioral response of lizards to climate change? in V. Bels and A. P. Russell, editors. Lizard behavior: evolutionary and mechanistic perspectives. CRC Press, Boca Raton, Florida, USA

Porter, W. P., and F. C. James. 1979. Behavioral implications of mechanistic ecology II: the African Rainbow Lizard, Agama agama. Copeia 1979:594-619.

Porter, W. P., J. W. Mitchell, W. A. Beckman, and C. B. DeWitt. 1973. Behavioral implications of mechanistic ecology - thermal and behavioral modeling of desert ectotherms and their microenvironment. Oecologia 13:1-54.

Porter, W. P., J. L. Sabo, C. R. Tracy, O. J. Reichman, and N. Ramankutty. 2002. Physiology on a landscape scale: plant-animal interactions. Integrative and Comparative Biology 42:431-453.

R Development Core Team. 2012. R: a language and environment for statistical computing. R Foundation for Statistical Computing, Vienna, Austria. http://www.R-project.org/

Reedy, A. M., D. Zaragoza, and D. A. Warner. 2013. Maternally chosen nest sites positively affect multiple components of offspring fitness in a lizard. Behavioral Ecology 24:39-46.

Riddell, E. A., E. K. Apanovitch, J. P. Odom, and M. W. Sears. 2017. Physical calculations of resistance to water loss improve predictions of species range models. Ecological Monographs 87:21-33.

Roberts, J. B., and H. B. Lillywhite. 1980. Lipid barrier to water exchange in reptile epidermis. Science 207:1077-1079.

Schmidt-Nielsen, K. 1964. Desert animals: physiological problems of heat and water. Dover Publications, New York, New York, USA 
Schmidt-Nielsen, B., and K. Schmidt-Nielsen. 1950. Evaporative water loss in desert rodents in their natural habitat. Ecology 31:75-85.

Schwarzkopf, L., M. J. Caley, and M. R. Kearney. 2016. One lump or two? Explaining a major latitudinal transition in reproductive allocation in a viviparous lizard. Functional Ecology 30:13731383.

Sears, M. W., M. J. Angilletta, M. S. Schuler, J. Borchert, K. F. Dilliplane, M. Stegman, T. W. Rusch, and W. A. Mitchell. 2016. Configuration of the thermal landscape determines thermoregulatory performance of ectotherms. Proceedings of the National Academy of Sciences USA 113:10595-10600.

Seely, M. K., J. R. Henschel, and J. W. Hamilton. 2005. Long-term data show behavioural fog collection adaptations determine Namib Desert beetle abundance. South African Journal of Science 101:570-572.

Sharpe, P. J. H., and D. W. DeMichele. 1977. Reaction kinetics of poikilotherm development. Journal of Theoretical Biology 64:649-670.

Shimmin, G. A., J. Skinner, and R. V. Baudinette. 2002. The warren architecture and environment of the southern hairy-nosed wombat (Lasiorhinus latifrons). Journal of Zoology 258:469-477.

Shine, R. 1971. The ecological energetics of the scincid lizard, Egernia cunninghami (Gray, 1832). Honours. Australian National University, Canberra, Australian Capital Territory, Australia.

Sinervo, B., et al. 2010. Erosion of lizard diversity by climate change and altered thermal niches. Science 328:894-899.

Spiegel, O., S. T. Leu, A. Sih, S. S. Godfrey, and C. M. Bull. 2015. When the going gets tough: behavioural type-dependent space use in the sleepy lizard changes as the season dries. Proceedings of the Royal Society B 282:20151768.

Sunday, J. M., A. E. Bates, M. R. Kearney, R. K. Colwell, N. K. Dulvy, J. T. Longino, and R. B. Huey. 2014. Thermal-safety margins and the necessity of thermoregulatory behavior across latitude and elevation. Proceedings of the National Academy of Sciences USA 11:5610-5615.
Tewksbury, J. J., R. B. Huey, and C. A. Deutsch. 2008. Putting the heat on tropical animals. Science 230:1296-1297.

Tracy, C. R. 1976. A model of the dynamic exchanges of water and energy between a terrestrial amphibian and its environment. Ecological Monographs 46:293-326.

Tracy, C. R., T. Tixier, C. L. Nöene, and K. A. Christian. 2014. Field hydration state varies among tropical frog species with different habitat use. Physiological and Biochemical Zoology 87:197-202.

Urban, M. C. 2015. Accelerating extinction risk from climate change. Science 348:571-573.

Urban, M. C., et al. 2016. Improving the forecast for biodiversity under climate change. Science 353:aad8466.

Uvarov, B. P. 1931. Insects and climate. Transactions of the Royal Entomological Society of London 79:1-232.

Veloz, S. D., J. W. Williams, J. L. Blois, F. He, B. Otto-Bliesner, and Z. Liu. 2012. No-analog climates and shifting realized niches during the late quaternary: implications for 21st-century predictions by species distribution models. Global Change Biology 18:1698-1713.

Warburg, M. R. 1965. The influence of ambient temperature and humidity on the body temperature and water loss from two Australian lizards, Tiliqua rugosa (Gray) (Scincidae) and Amphibolurus barbatus cuvier (Agamidae). Australian Journal of Zoology 13:331-350.

Warming, E. 1909. Oecology of plants: an introduction to the study of plant communities. Clarendon Press, Oxford, UK.

White, C. R., T. M. Blackburn, J. S. Terblanche, E. Marais, M. Gibernau, and S. L. Chown. 2007. Evolutionary responses of discontinuous gas exchange in insects. Proceedings of the National Academy of Sciences USA 104:8357-8361.

Wilson, K. J. 1974. The relationship of oxygen supply for activity to body temperature in four species of lizards. Copeia 1974:920-934.

Wright, C. D., M. L. Jackson, and D. F. DeNardo. 2013. Meal consumption is ineffective at maintaining or correcting water balance in a desert lizard, Heloderma suspectum. Journal of Experimental Biology 216:1439-1447.

\section{SUPPORTING INFORMATION}

Additional supporting information may be found online at: http://onlinelibrary.wiley.com/doi/10.1002/ecm.1326/full

Data Availability

Data associated with this study are available from Zenodo: https://zenodo.org/badge/latestdoi/40096662 